\title{
Adsorption-Desorption Surface Bindings, Kinetics, and Mass Transfer Behavior of Thermally and Chemically Treated Great Millet Husk towards Cr(VI) Removal from Synthetic Wastewater
}

\author{
Anuj Kumar Prajapati, Pushkar Verma, Satyansh Singh, and Monoj Kumar Mondal \\ Department of Chemical Engineering and Technology, Indian Institute of Technology (Banaras Hindu University), Varanasi, \\ 221005 Uttar Pradesh, India \\ Correspondence should be addressed to Monoj Kumar Mondal; mkmondal.che@itbhu.ac.in
}

Received 3 September 2021; Revised 29 November 2021; Accepted 3 January 2022; Published 28 January 2022

Academic Editor: Muhammad Raziq Rahimi Kooh

Copyright (c) 2022 Anuj Kumar Prajapati et al. This is an open access article distributed under the Creative Commons Attribution License, which permits unrestricted use, distribution, and reproduction in any medium, provided the original work is properly cited.

\begin{abstract}
This study reports the efficacy of adsorbents synthesized by thermal (TT-GMH) and chemical (CT-GMH) modification of great millet husk $(\mathrm{GMH})$ for the treatment of synthetic wastewater containing $\mathrm{Cr}(\mathrm{VI})$. The chemical modification of raw GMH was done by concentrated $\mathrm{H}_{2} \mathrm{SO}_{4}$ to increase the porosity and heterogeneity on the surface. The comparative investigations of physicochemical properties of synthesized adsorbents were examined by point of zero charge $\left(\mathrm{pH}_{\mathrm{pzc}}\right)$, BET surface area, SEMEDX, FTIR, and XRD analyses. The results revealed that CT-GMH had around three times higher surface area and more porous structure as compared to TT-GMH. The adsorption experiments were executed in batch mode to examine the impact of parameters governing the adsorption process. For $\mathrm{Cr}(\mathrm{VI})$ solution of $25 \mathrm{mg} / \mathrm{L}$, adsorbent dose of $4 \mathrm{~g} / \mathrm{L}$, temperature of $25^{\circ} \mathrm{C}$, and shaking speed of $150 \mathrm{RPM}$, the maximum removal for TT-GMH was attained at $\mathrm{pH} 1$ and contact time $150 \mathrm{~min}$, while for $\mathrm{CT}-\mathrm{GMH}$, maximum removal was attained at $\mathrm{pH} 2$ and contact time $120 \mathrm{~min}$. The experimental results fitted to the rate kinetic equations showed that for both TT-GMH and CT-GMH, adsorbents followed the quasi-second-order kinetic model during the adsorption process. Further, results revealed that the adsorption process was endothermic and Sips isotherm model was followed for both TT-GMH and CT-GMH. Based on the Sips isotherm, maximum uptake capacity for TT-GMH and CTGMH was noted to be 16 and $22.21 \mathrm{mg} / \mathrm{g}$, respectively. Among the tested mass transfer models, liquid film diffusion model was followed during the adsorption process of both the adsorbents. The desorption study revealed that TT-GMH and CT-GMH give $69.45 \%$ and $74.48 \%$ removal, respectively, up to six cycles.
\end{abstract}

\section{Introduction}

Toxic heavy metals and dyes pertaining to water pollution have been a serious concern for environmental and ecological researchers. Rapid industrialization and regular human activities are mainly responsible for the increment of these pollutants in the environment and cause side effects and severe health issues to humans, live animals, and plant development [1]. Chromium, a heavy and d-block metal, exists in the trivalent $(\mathrm{Cr}(\mathrm{III}))$ and hexavalent $(\mathrm{Cr}(\mathrm{VI}))$ state in wastewater. Compared to $\mathrm{Cr}(\mathrm{VI}), \mathrm{Cr}(\mathrm{III})$ is insoluble and also an essential nutrient in small quantities required by microorganisms and humans to control the insulin, sugar, and lipid metabolism
[2], while amounts of $\mathrm{Cr}(\mathrm{VI})$ are highly lethal because of its carcinogenic, mutagenic, and teratogenic effects [3-5]. The $\mathrm{Cr}(\mathrm{VI})$ is present in the effluents from alloy making processes, tanneries, wood preservation paint and pigments, electroplating, and stainless steel industries $[4,6]$. The permissible limit for $\mathrm{Cr}(\mathrm{VI})$ in industrial effluents is limited to $2 \mathrm{mg} / \mathrm{L}$, and in potable water, it is restricted to 0.05 to $0.1 \mathrm{mg} / \mathrm{L}$ by Indian Standards (IS), World Health Organization (WHO), and United States Environmental Protection Agency (USEPA) $[2,7]$. The industries must treat their effluent by an economical water treatment technology to reduce $\mathrm{Cr}(\mathrm{VI})$ concentrations up to the tolerance limit. Then, the treated effluent is discharged into the aquatic ecosystem or environment. 
The technologies such as chemical precipitation [7], electrochemical precipitation [8], chemical coagulation [9], adsorption [2, 4], photocatalysis [10], solvent extraction [11], ion exchange [12], and membrane separation [13] are advance technologies that are used for the treatment of $\mathrm{Cr}(\mathrm{VI})$ from industrial wastewater. Except for adsorption, other technologies cannot be used for industrial-scale operation due to low removal efficiency towards $\mathrm{Cr}(\mathrm{VI})$, low selectivity for target pollutant species, high operational cost, and the probability of generation of by-product which may be toxic $[2,14]$. Adsorption process is an attractive alternative treatment process to effectively remove $\mathrm{Cr}(\mathrm{VI})$ ions from wastewater due to low cost of operation, lesser consumption of hazardous chemicals, and minimum production of treated waste $[2,4,15,16]$.

Several low-cost adsorbents have been used to remove pollutant ions from wastewater; these include nonliving biomass, waste biomass, algal biomass, or microbial biomass [17]. Also, activated carbon, nanoporous activated carbon, biochar, and chemically modified biochar prepared from aloe vera waste [18], garlic stem [19], and coconut shell [20] were also used for adsorption of pollutant species from wastewater. For reducing the $\mathrm{Cr}(\mathrm{VI})$ ion concentration from the aqueous solution, adsorbents such as waste tea [21], raw straw [22], rice husk [23], orange peel [24], walnut shell [25], Ziziphus jujuba cores as waste lignocellulosic material [26], and eggshell membranes of different birds [27] had been investigated. In the present study, abundantly available agricultural waste of sorghum bicolor (great millet husk, $(\mathrm{GMH}))$ husk has been used as a raw material for producing cost-effective adsorbent by thermal and chemical treatment. The physicochemical properties of prepared adsorbents were examined by point of zero charge $\left(\mathrm{pH}_{\mathrm{pzc}}\right)$, BrunauerEmmett-Teller (BET) surface area, scanning electron microscopy coupled with energy dispersive X-ray (SEMEDX), Fourier transform infrared spectroscopy (FTIR), and $\mathrm{X}$-ray diffraction (XRD) analyses. The influence of the initial $\mathrm{pH}$ of $\mathrm{Cr}(\mathrm{VI})$ solution and adsorbent dose was examined to obtained the optimum value of $\mathrm{pH}$ and dose for $\mathrm{Cr}(\mathrm{VI})$ uptake onto TT-GMH and CT-GMH adsorbents. The kinetic and isotherm models for the removal of $\mathrm{Cr}(\mathrm{VI})$ by TT-GMH and CT-GMH were studied through experimental data of time and concentration parameters, respectively. Thermodynamic modeling for energy parameters such as Gibbs energy $\left(\Delta G^{\circ}\right)$, entropy $\left(\Delta S^{\circ}\right)$, and enthalpy $\left(\Delta H^{\circ}\right)$ was calculated by influences of temperature for the removal of $\mathrm{Cr}$ (VI) by TT-GMH and CT-GMH adsorbents. Besides, the mechanism governing the mass transfer operation during adsorption was examined.

\section{Material and Methods}

2.1. Adsorbent Preparation. Great millet husk (GMH) was collected from the nearby villages of Varanasi. It was then washed with distilled water to remove dirt and dried in a thermostatically controlled oven at $105^{\circ} \mathrm{C}$ for $12 \mathrm{~h}$. Two types of adsorbent were prepared from the husk. Thermally treated adsorbent (TT-GMH) was prepared by vigorous boiling of GMH until the color was removed. Chemically treated adsorbent (CT-GMH) was prepared by adding concentrated $\mathrm{H}_{2} \mathrm{SO}_{4}$ to the husk in $1: 1$ weight ratio; then, the blend was agitated with the help of a magnetic stirrer. After mixing, the blend was filtered, and the filtrate was washed repeatedly with double distilled water till the $\mathrm{pH}$ of the filtrate reached to 7 . Particles were then subjected to drying for $24 \mathrm{~h}$ in an oven, pulverized into fine powder, and sieved for different sizes.

2.2. Reagents and Solutions. All the AR grade chemicals $\left(\mathrm{K}_{2} \mathrm{Cr}_{2} \mathrm{O}_{7}, \mathrm{H}_{2} \mathrm{SO}_{4}, \mathrm{NaOH}, \mathrm{HCl}\right.$, diphenyl carbazide, and acetone) were used during experiments and purchased from Merck and SRL India. Distilled water was used to prepare $1000 \mathrm{mg} / \mathrm{L}$ stock solution of $\mathrm{Cr}$ (VI) by dissolving $2.828 \mathrm{~g}$ of $\mathrm{K}_{2} \mathrm{Cr}_{2} \mathrm{O}_{7}$. The desired concentration of $\mathrm{Cr}(\mathrm{VI})$ solution was obtained by diluting the stock solution. Carbazide solution was prepared by dissolving $500 \mathrm{mg}$ of 1,5-diphenyl carbazide in $100 \mathrm{~mL}$ acetone, and sulfuric acid $(6 \mathrm{~N})$ was synthesized by dilution using double distilled water.

2.3. Analytical Methods and Instruments Used. The adsorbent prepared from thermally and chemically treated great millet husk (TT-GMH and CT-GMH) was characterized using BET surface area, SEM-EDX, FTIR, and XRD analyses. The instruments used during batch adsorption process were a $\mathrm{pH}$ meter measuring the $\mathrm{pH}$ of solution, a shaking incubator, an oven for drying of adsorbent, and a UV-visible spectrophotometer for measuring the concentration of $\mathrm{Cr}(\mathrm{VI})$. The detailed specification (Table S1) and procedure (Procedure S1) for analytical instruments have been given in supplementary material, the absorbance at which $\mathrm{Cr}(\mathrm{VI})$ concentration finds maximum absorption.

2.4. Batch Adsorption Studies. Experiments in batch mode operation were performed for removal of $\mathrm{Cr}$ (VI) from aqueous solution. Excluding the impact of temperature, the rests of the experiments were performed at ambient temperature. The impact of various operating parameters like initial $\mathrm{Cr}(\mathrm{VI})$ concentration $(5-100 \mathrm{mg} / \mathrm{L}), \mathrm{pH}$ of the adsorbate (1-10), temperature $\left(25-40^{\circ} \mathrm{C}\right)$, contact time $(0-180 \mathrm{~min})$, and adsorbent dose $(2-10 \mathrm{~g} / \mathrm{L})$ was examined during adsorption onto adsorbents TT-GMH and CT-GMH. The $50 \mathrm{~mL}$ solution of predetermined concentration was used to perform the experiments is $100 \mathrm{~mL}$ flasks. The desired solution $\mathrm{pH}$ was obtained with $0.1 \mathrm{~N} \mathrm{H}_{2} \mathrm{SO}_{4}$ and $0.1 \mathrm{~N} \mathrm{NaOH}$ solutions. The solution with varying adsorbent doses and at constant temperature was placed in a shaking incubator running at a constant speed of $150 \mathrm{rpm}$. The flasks were taken out at regular interval of time, and the adsorbent was separated by using centrifuge. The $\mathrm{Cr}(\mathrm{VI})$ ion concentration in aqueous solution was measured by employing a spectrophotometer by measuring the deep red-violet-colored complex. This complex was formed in an acidic medium by the reaction of $\mathrm{Cr}(\mathrm{VI})$ and 1,5-diphenylcarbazide, and the maximum absorbance of $\mathrm{Cr}(\mathrm{VI})$ was measured at $540 \mathrm{~nm}$ [28]. The removal percentage was enumerated by employing

$$
\text { \%Removal of } \operatorname{Cr}(\mathrm{VI})=\frac{\left(C_{0}-C_{t}\right) \times 100}{C_{o}}
$$


The uptake capacity was determined by employing

$$
\operatorname{Uptake} \operatorname{capacity}(q)=\frac{\left(C_{0}-C_{t}\right) V}{W},
$$

where $q_{\mathrm{e}}$ denotes as uptake capacity in milligram/gram. $C_{\mathrm{o}}$ denotes initial concentration of $\mathrm{Cr}(\mathrm{VI})$, while $C_{\mathrm{t}}$ denotes concentration of $\mathrm{Cr}(\mathrm{VI})$ at time $t$ in $(\mathrm{mg} / \mathrm{L}) . V$ denotes volume of $\mathrm{Cr}(\mathrm{VI})$ solution in litre, and $W$ denotes weight of adsorbent in grams.

\section{Results and Discussion}

3.1. Physicochemical Characteristics of the Adsorbent. The $\mathrm{pH}_{\mathrm{pzc}}$ of the adsorbents TT-GMH and CT-GMH was found to be 5.9 and 4, respectively, (Figure 1). At $\mathrm{pH}$, less than pHpzc, the adsorbents have higher density of positively charged ions. Strong attraction force on anions is exerted by these surface positive functional groups $[18,29]$. The essential information about adsorption limit can be obtained from the surface area of the adsorbent which is an intrinsic property. The BET surface area of TT-GMH was noted to be $9.00280 \mathrm{~m}^{2} / \mathrm{g}$ with a total pore volume of $0.00536 \mathrm{~cm}^{3} / \mathrm{g}$. The BET surface area of $26.7815 \mathrm{~m}^{2} / \mathrm{g}$ with total pore volume $0.03085 \mathrm{~cm}^{3} / \mathrm{g}$ was seen for CT-GMH. It was found that chemical treatment with $\mathrm{H}_{2} \mathrm{SO}_{4}$ enhanced the specific surface area and total pore volume [18]. The analysis surface morphology of the adsorbent by SEM revealed that before, adsorption surface was rough with some pores for both TT-GMH and CT-GMH as can be seen from Figures 2(a) and 2(e). The SEM micrographs of TTGMH and CT-GMH after adsorption (Figures 2(c) and $2(\mathrm{~g})$ ) showed smooth surface covering of the pores. The EDX analysis was performed for the elemental composition of the sample. Chemical composition of TT-GMH and CTGMH before and after adsorption is summarized in Table 1. Figures 2(d) and 2(h) showed $\mathrm{Cr}(\mathrm{VI})$ peaks associated with adsorbents TT-GMH and CT-GMH after $\mathrm{Cr}(\mathrm{VI})$ adsorption while no $\mathrm{Cr}(\mathrm{VI})$ peaks for the bare adsorbents were detected (Figures 2(b) and 2(f)). These results confirmed the adsorption of $\mathrm{Cr}(\mathrm{VI})$ ions on the surface TT-GMH and CT-GMH. The FTIR spectra for TT-GMH and CT-GMH were recorded in the range of $4000-400 \mathrm{~cm}^{-1}$ wave number. For both the adsorbents, presence of stretching for -OH can be confirmed from peaks of $3376.5 \mathrm{~cm}^{-1}$ for TT-GMH and $3392.5 \mathrm{~cm}^{-1}$ for CT-GMH because of inter- and intramolecular hydrogen bonding [22]. The $\mathrm{O}-\mathrm{H}$ groups associated with adsorbents were observed in a broad range of wavenumbers attributing the existence of bare and carboxylic acid bonded $\mathrm{O}-\mathrm{H}$ groups. Additionally, peaks at $2915.1 \mathrm{~cm}^{-1}$ for TT-GMH plot and $2923.8 \mathrm{~cm}^{-1}$ for CT-GMH plot showed the presence of $\mathrm{H}-\mathrm{C}-\mathrm{H}$ stretching. Peaks at $1640 \mathrm{~cm}^{-1}$ and $1608 \mathrm{~cm}^{-1}$ correspond to vibrations of $\mathrm{C}=\mathrm{O}$ bonds of carboxylic groups and ester groups, correspondingly. The peak at $1608 \mathrm{~cm}^{-1}$ for CT-GMH was attributed to the N-H bond. A shift in the peaks of $\mathrm{Cr}(\mathrm{VI})$ adsorbed TT-GMH and CT-GMH shown in Figure 3 confirmed the active participation in adsorption by hydroxyl, alkyl, and ketone groups. In the case of TT$\mathrm{GMH}$ as an adsorbent, $\mathrm{O}-\mathrm{H}, \mathrm{C}-\mathrm{H}, \mathrm{C}=\mathrm{C}$, and $\mathrm{C}=\mathrm{O}$ peaks

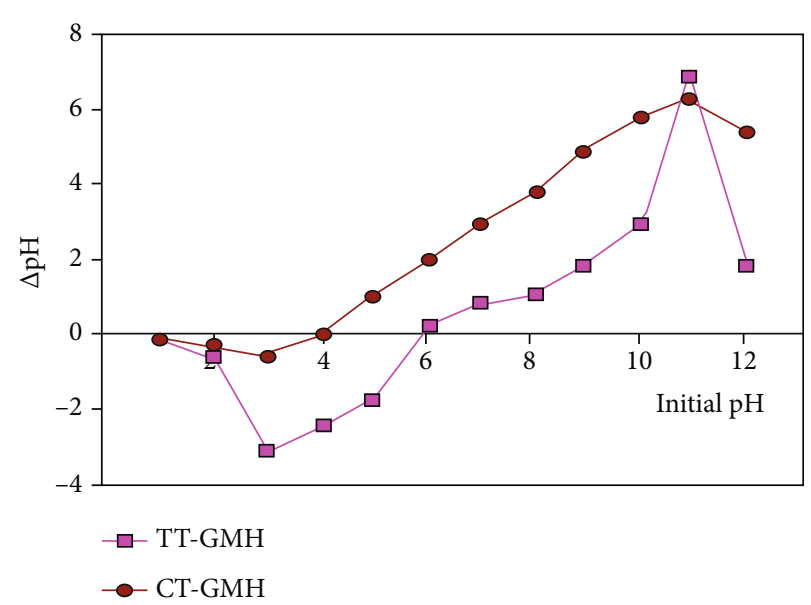

FIgure 1: Point of zero charge of adsorbents TT-GMH and CT$\mathrm{GMH}$.

shifted from 3475 to 3467,2926 to 2918,1620 to 1639 , and 1120 to $1093 \mathrm{~cm}^{-1}$, respectively, while in case of CT-GMH as an adsorbent, $\mathrm{O}-\mathrm{H}, \mathrm{C}-\mathrm{H}, \mathrm{C}=\mathrm{C}$, and $\mathrm{C}=\mathrm{O}$ peaks shifted from 3490 to 3485,2938 to 2922,1612 to 1635 , and 1130 to $1099 \mathrm{~cm}^{-1}$, respectively. Apart from those, new peaks at $452 \mathrm{~cm}^{-1}$ for TT-GMH and at $452 \mathrm{~cm}^{-1}$ for CT-GMH appeared after adsorption. XRD analysis of TT-GMH and CT-GMH before and after adsorption is presented in Figure 4 . In the case of TT-GMH before adsorption, a broad peak at $2 \theta=22.5^{\circ}$ corresponds to crystalline peak associated with cellulosic carbon of GMH [28]. After adsorption, a slight increase in peak intensity and marginal shift in $2 \theta$ were observed. This might be due to surface adsorption of $\mathrm{Cr}(\mathrm{VI})$ onto TT-GMH. In the case of CT-GMH before adsorption, three sharp peaks at $2 \theta=18^{\circ}, 22.5^{\circ}$, and $25^{\circ}$ were observed. The sharp peak in the case of CT-GMH before might be due to intensification of crystalline cellulose because of decomposition of hemicellulose during chemical treatment $[28,30]$. After adsorption, a slight increase in peak intensity and marginal shift in $2 \theta$ were also observed in the case of CT-GMH. Similar XRD pattern was also reported by Narayan et al. [29].

\subsection{Batch Adsorption Experiments}

3.2.1. Impact of Contact Time. The impact of contact time on $\mathrm{Cr}(\mathrm{VI})$ adsorption on TT-GMH and CT-GMH was explored by changing the time from 0 to $150 \mathrm{~min}$. The experiment was performed at $\mathrm{pH} 2$ for TT-GMH and CT-GMH, keeping the dose of adsorbent constant at $4 \mathrm{~g} / \mathrm{L}$ (Figure 5(a)). The saturation level for $\mathrm{Cr}(\mathrm{VI})$ adsorption on adsorbents was reached at $150 \mathrm{~min}$ for TT-GMH and $120 \mathrm{~min}$ for CT-GMH. Thus, chemical modification of GMH imparts lower equilibrium time and higher removal (\%) for $\mathrm{Cr}(\mathrm{VI})$ ions [22]. After the equilibrium is attained, the removal efficiency remained almost constant. Initially, the number of vacant site for the adsorption process is large; however, once the equilibrium is attained, the possibility of repulsion between adsorbed $\mathrm{Cr}(\mathrm{VI})$ and $\mathrm{Cr}(\mathrm{VI})$ present in aqueous solution prevails [18]. This might be the reason for saturation in removal once the equilibrium is attained. 


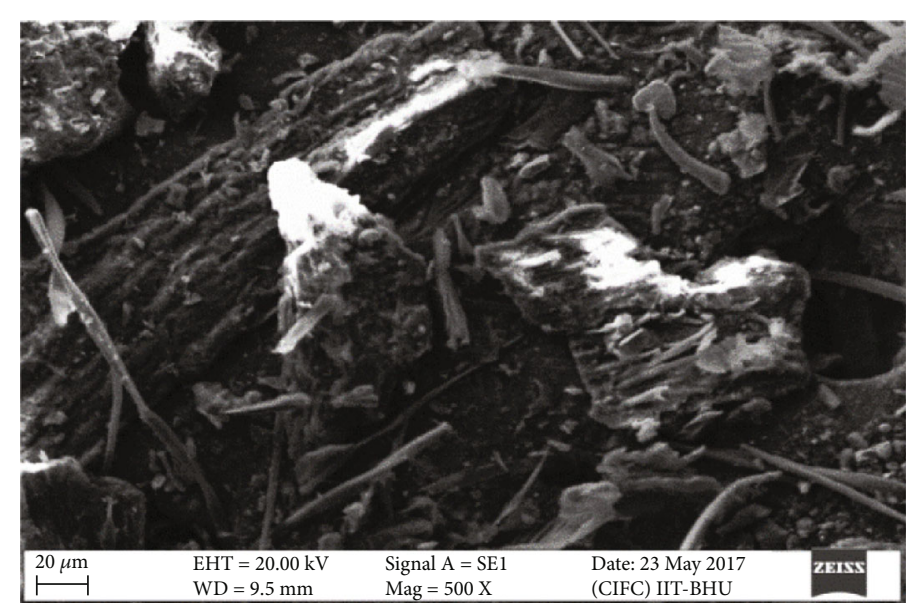

(a)

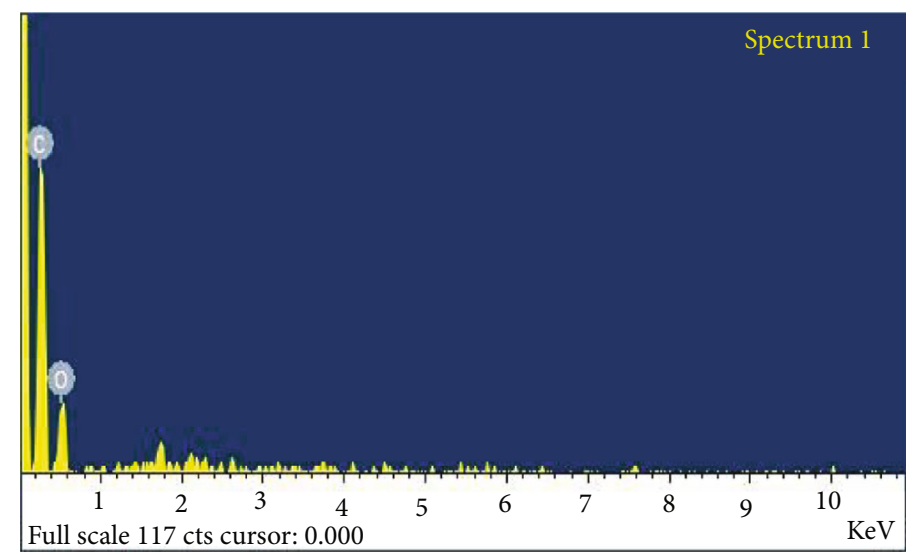

(b)

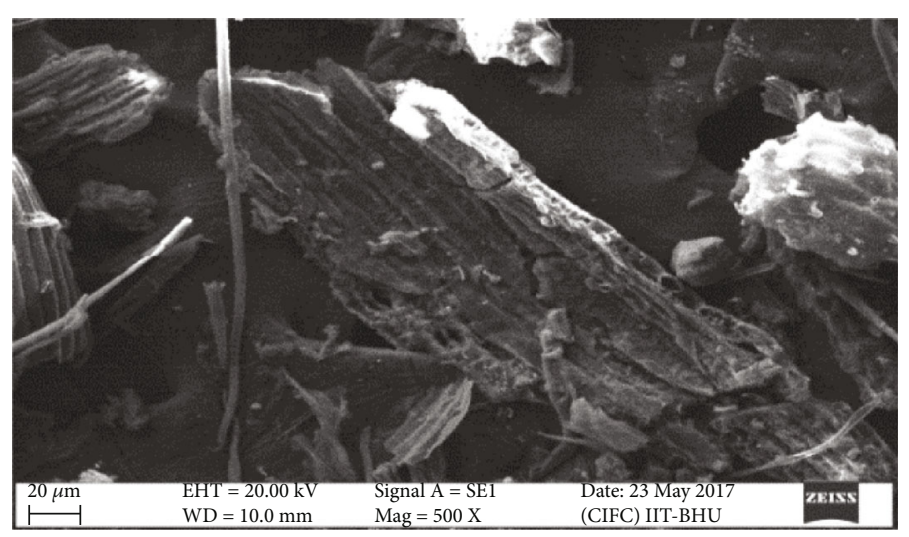

(c)

Figure 2: Continued. 


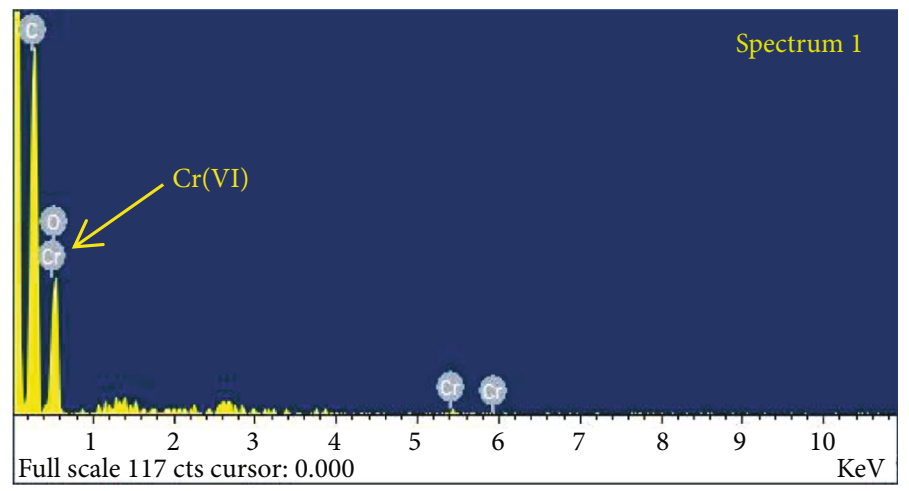

(d)

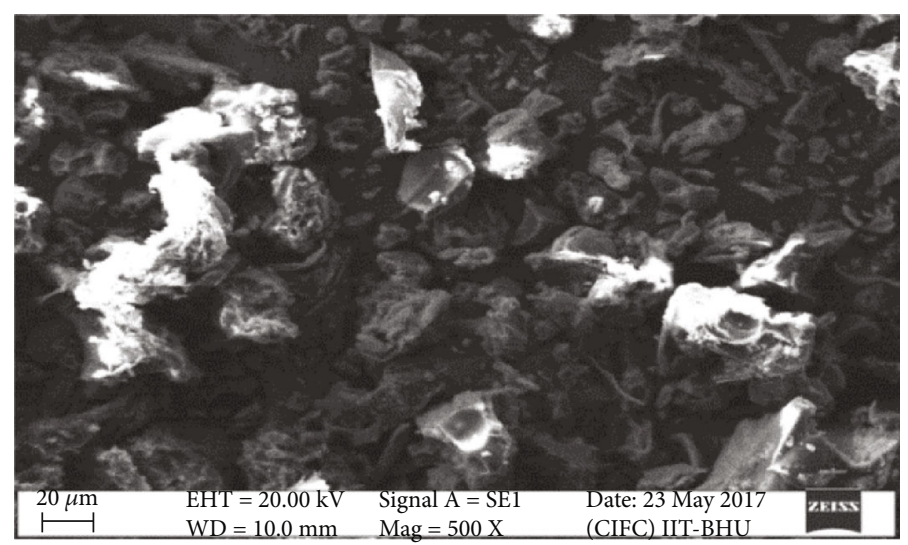

(e)

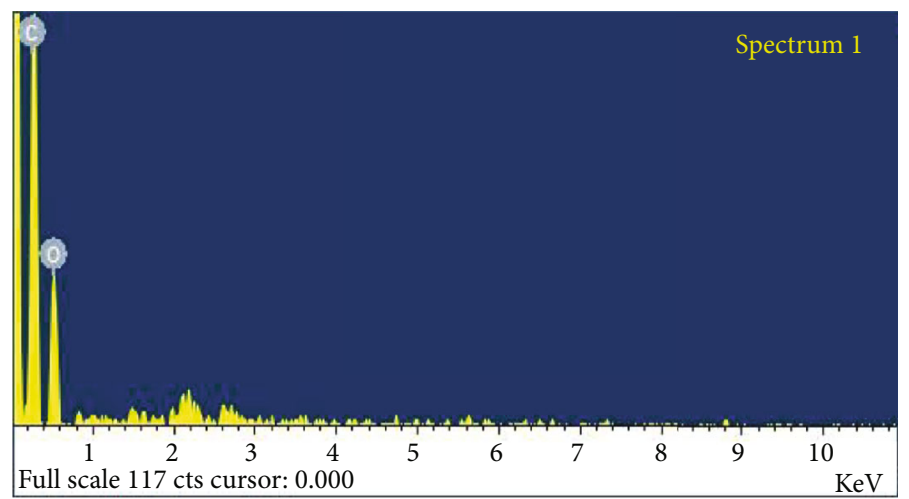

(f)

FIgURE 2: Continued. 


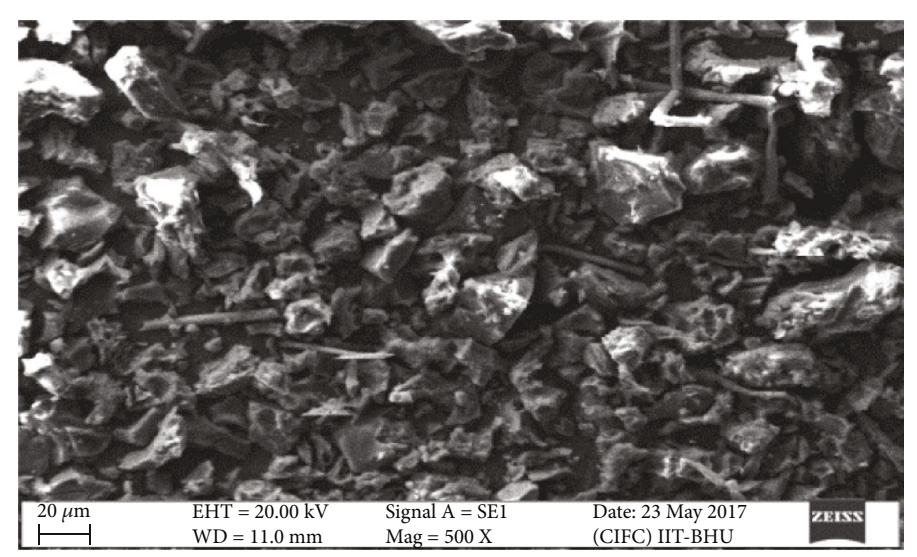

(g)

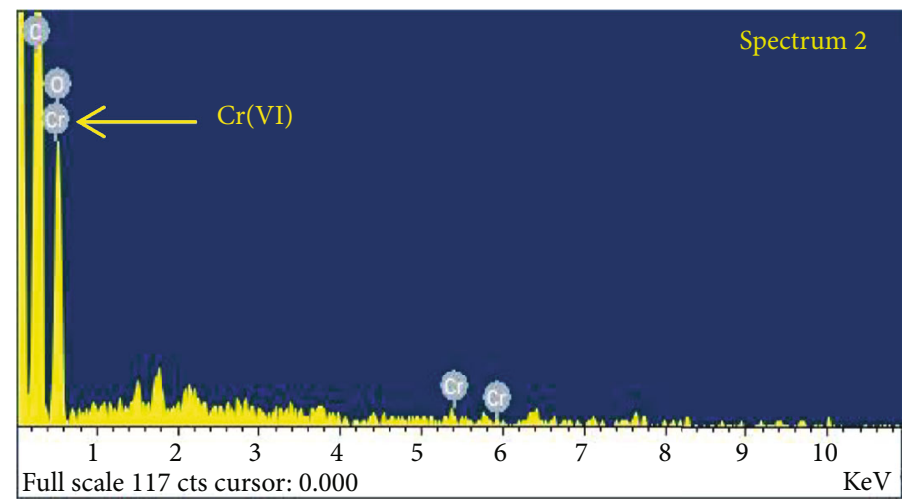

(h)

Figure 2: SEM-EDX analysis of (a, b) TT-GMH before adsorption, (c, d) TT-GMH after adsorption, (e, f) CT-GMH before adsorption, and (g, h) CT-GMH after adsorption.

TABLE 1: Chemical composition of TT-GMH and CT-GMH before and after adsorption of $\mathrm{Cr}(\mathrm{VI})$.

\begin{tabular}{lcccc}
\hline $\begin{array}{l}\text { Elements } \\
\text { (wt\%) }\end{array}$ & $\begin{array}{c}\text { TT-GMH } \\
\text { Before } \\
\text { adsorption }\end{array}$ & $\begin{array}{c}\text { TT-GMH } \\
\text { After } \\
\text { adsorption }\end{array}$ & $\begin{array}{c}\text { CT-GMH } \\
\text { Before } \\
\text { adsorption }\end{array}$ & $\begin{array}{c}\text { CT-GMH } \\
\text { After } \\
\text { adsorption }\end{array}$ \\
\hline C & 56.65 & 64.08 & 65.09 & 57.98 \\
O & 43.35 & 35.87 & 34.91 & 41.63 \\
Cr & 0.00 & 0.05 & 0.00 & 0.39 \\
\hline
\end{tabular}

3.2.2. Impact of Initial $p H$. Figure 5(b) depicts the impact of initial $\mathrm{pH}$ on removal of $\mathrm{Cr}(\mathrm{VI})$. The $\mathrm{pH}$ of the adsorbate solution has proven importance in the adsorption process $[18,21]$. The tendency of metal ion solubility, the strength of functional groups associated with adsorbent, and strength of ionization of adsorbent during the adsorption process are governed by $\mathrm{pH}$ of solution [22]. Therefore, $\mathrm{pH}$ of solution is very crucial during the adsorption process. The impact of initial $\mathrm{pH}$ on removal of $\mathrm{Cr}(\mathrm{VI})$ was perceived between 1 and 10 . It was witnessed that the removal (\%) decreased from 98.64 to $12.84 \%$ for TT-GMH with an increase in the $\mathrm{pH}$ from 1 to 10 ; however, for CT-GMH, percentage removal increased from 97.75 to $99.5 \%$ when $\mathrm{pH}$ was increased from 1 to 2 , after $\mathrm{pH} 2$ removal decreased all the way up to $20.48 \%$ at $\mathrm{pH} 10$. Higher removal percentage at low $\mathrm{pH}$ is due to the presence of anions such as $\mathrm{HCrO}_{4}^{-}$ , $\mathrm{CrO}_{4}^{-}$, and $\mathrm{Cr}_{2} \mathrm{O}_{7}^{-2}$, in an acidic environment. Hence, with lower initial $\mathrm{pH}$ of adsorbate solution, increased $\mathrm{Cr}(\mathrm{VI})$ removal occurred [31]. However, at higher $\mathrm{pH}$, removal (\%) decreases because of upsurge in the hydroxyl ion concentration on the adsorbent surface which builds up a repulsive force between the anions and the negatively charged surface [32].

3.2.3. Impact of Adsorbent Dose. A decisive parameter for analyzing the adsorption process is the dose of the adsorbent. The impact of dose of adsorbent on adsorption process is presented in Figure 5(c). Results showed that removal (\%) of $\mathrm{Cr}(\mathrm{VI})$ improved with upsurge in the dose of adsorbent varying from 2 to $10 \mathrm{~g} / \mathrm{L}$. With an increase in adsorbent dose, the number of fresh and bare active sites of adsorbent for $\mathrm{Cr}(\mathrm{VI})$ increased, resulting in upsurge in removal (\%) $[33,34]$. As the adsorbent dose increases, the uptake capacity reflected the contrasting nature. For both adsorbents (TTGMH and CT-GMH), the uptake capacity decreases with increase in dose from 2 to $10 \mathrm{~g} / \mathrm{L}$ due to existence of unadsorbed active sites.

3.2.4. Impact of Initial Cr(VI) Concentration. Figure 5(d) depicts the impact of $\mathrm{Cr}(\mathrm{VI})$ concentration on the removal 


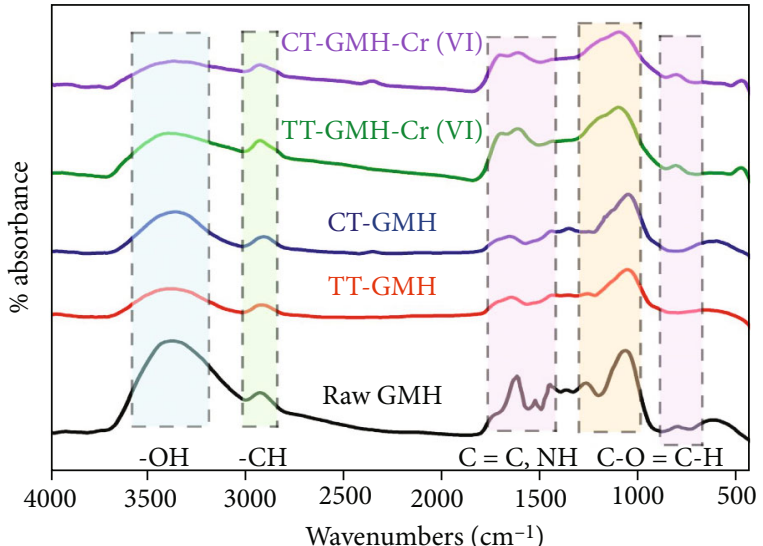

Figure 3: FTIR spectrum of raw GMH and adsorbents TT-GMH and CT-GMH before and after adsorption of $\mathrm{Cr}(\mathrm{VI})$.

(\%) of adsorbents, TT-GMH and CT-GMH. The concentration of the solution provides the driving force for $\mathrm{Cr}(\mathrm{VI})$ ions to mitigate the mass transfer limitations among the adsorbate and adsorbent phase [35]. Moreover, high concentrations of $\mathrm{Cr}(\mathrm{VI})$ solution facilitate the accumulation of adsorbate particles at adsorbent surface and occupy more adsorption site during the adsorption process. Meanwhile, it was perceived that uptake capacity decreased with upsurge in concentration from 5 to $200 \mathrm{mg} / \mathrm{L}$. This appears due to the increase in the ratio of $\mathrm{Cr}(\mathrm{VI})$ ion to adsorbent, since the higher ratio of $\mathrm{Cr}(\mathrm{VI})$ ion to adsorbent can saturate highenergy active sites and initiate the adsorption at lower energy sites of adsorbent causing decrease in uptake capacity $[36,37]$.

3.2.5. Impact of Temperature. Temperature of the medium imparts critical impact on the adsorption process. The temperature during the adsorption using TT-GMH and CT$\mathrm{GMH}$ as adsorbents was varied from 25 to $40^{\circ} \mathrm{C}$, and results are depicted in Figure 5(e). The maximum adsorption of $\mathrm{Cr}(\mathrm{VI})$ which was $99.56 \%$ using TT-GMH and $99.82 \%$ using $\mathrm{CT}-\mathrm{GMH}$ at $40^{\circ} \mathrm{C}$ was obtained. With the increase in temperature, the removal (\%) increased for both the adsorbents (TT-GMH and CT-GMH). With the rise in temperature, there might be rupture of chemical bonds associated with adsorbent leading to enhanced adsorption because of more numbers of active adsorption sites. Additionally, with the increase in temperature, the uptake capacity also increased due to increase in collision frequency among adsorbent and adsorbate [38].

3.2.6. Impact of RPM. In an adsorption study, it is crucial to study the impact of shaking speed since it is an energyintensive process and affects the adsorption capacity. The shaking speed was varied from 90 to 180 RPM keeping the rest of the parameters at optimum condition. The impact of shaking speed of removal of $\mathrm{Cr}(\mathrm{VI})$ is presented in Figure 5(f). It can be observed that with an increase in shaking speed, the \% removal of $\mathrm{Cr}(\mathrm{VI})$ increases up to $150 \mathrm{RPM}$ thereafter that it starts decreasing for both the adsorbents (TT-GMH and CT-GMH). The decrease in removal \% after

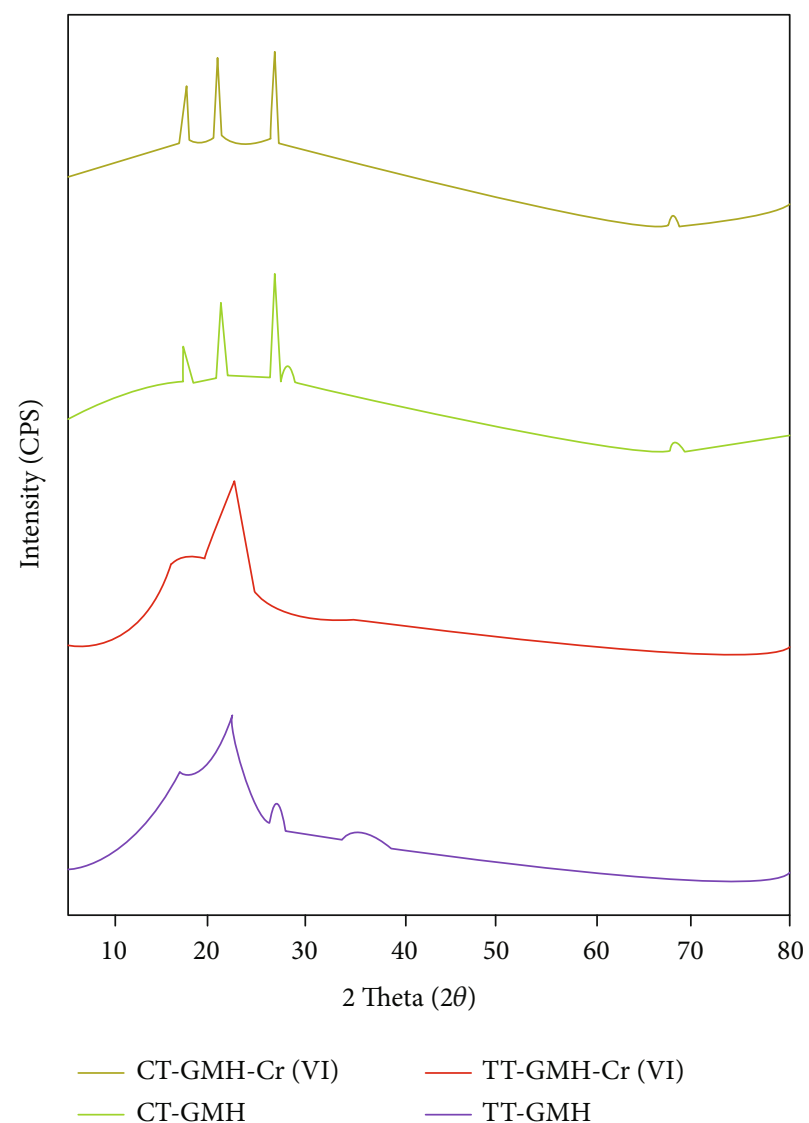

FIGURE 4: XRD spectrum of adsorbents TT-GMH and CT-GMH before and after adsorption of $\mathrm{Cr}(\mathrm{VI})$.

150 RPM might be due to extra energy possessed by the adsorbent resulting in cleavage of bonds formed between adsorbent molecules and $\mathrm{Cr}(\mathrm{VI})$ ions [39]. These results are in line with the results obtained by Gupta et al. [40].

3.3. Adsorption Kinetics. The adsorption kinetics examines the uptake rate of solute on the adsorbent surface during adsorption. This uptake rate decides the retention time of adsorbate at the solid-liquid interface and thus determines the rate-controlling mechanism. To evaluate the adsorption kinetics of $\mathrm{Cr}(\mathrm{VI})$ ions, the pseudo-first-order (Eq. S1) (Table S2 supplementary material), pseudo-second-order (Eq. S2), and Elovich models (Eq. S3) were tested. The results obtained for adsorption were fitted to Eqs. (S1), (S2), and (S3) and the kinetic results are shown in Figure 6. The calculated parameters for kinetics are tabulated in Table 2. The $R^{2}$ for quasi-second-order model for TT-GMH and CT-GMH was noted to be 0.9868 and 0.968 , respectively, which was higher than other tested models for both the adsorbents. Additionally, the error function $(\chi)$ was minimal for the quasi-second-order model, which validated that the model was best fitted with experimental data. Also, the experimental uptake capacity and uptake capacity $\left(q_{\mathrm{e}}\right)$ obtained by the quasi-secondorder model were closest. Thus, based on the value of correlation coefficient $\left(R^{2}\right)$ and the vicinity of uptake capacity, the quasi-second-order kinetic model was best 

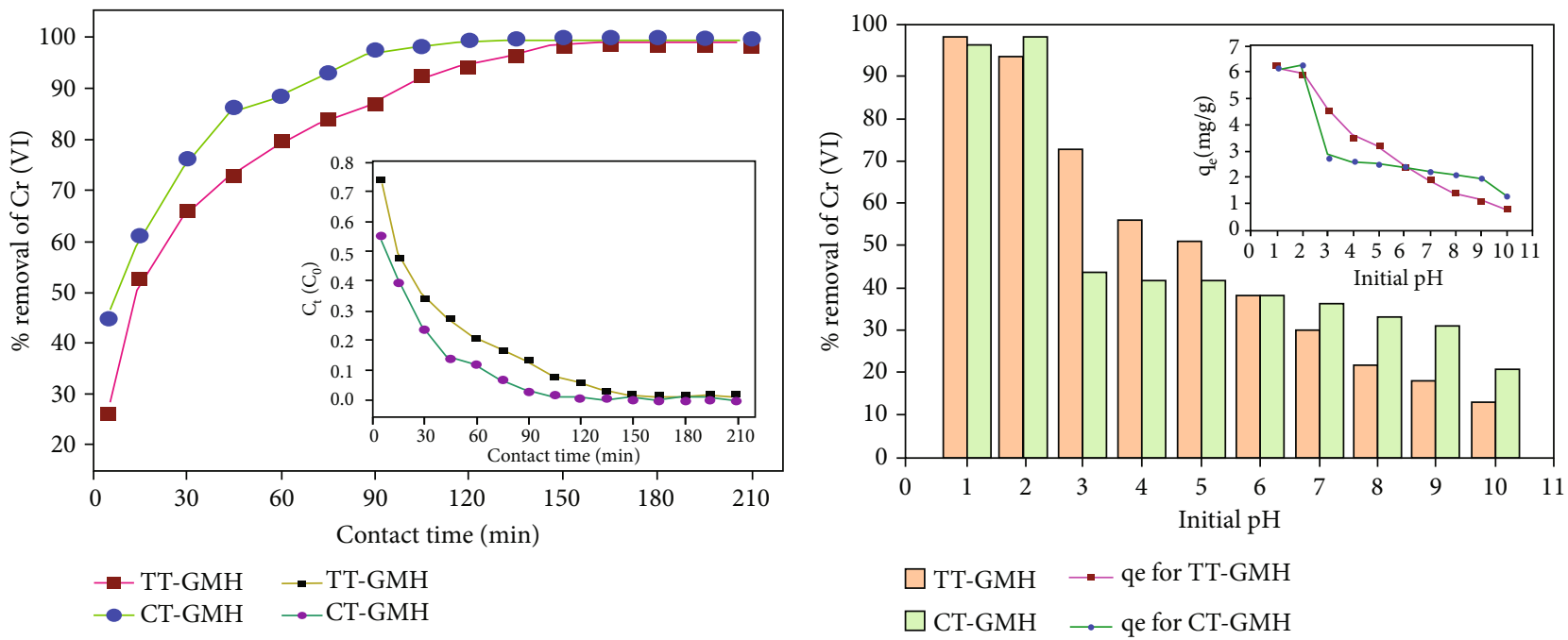

(a)
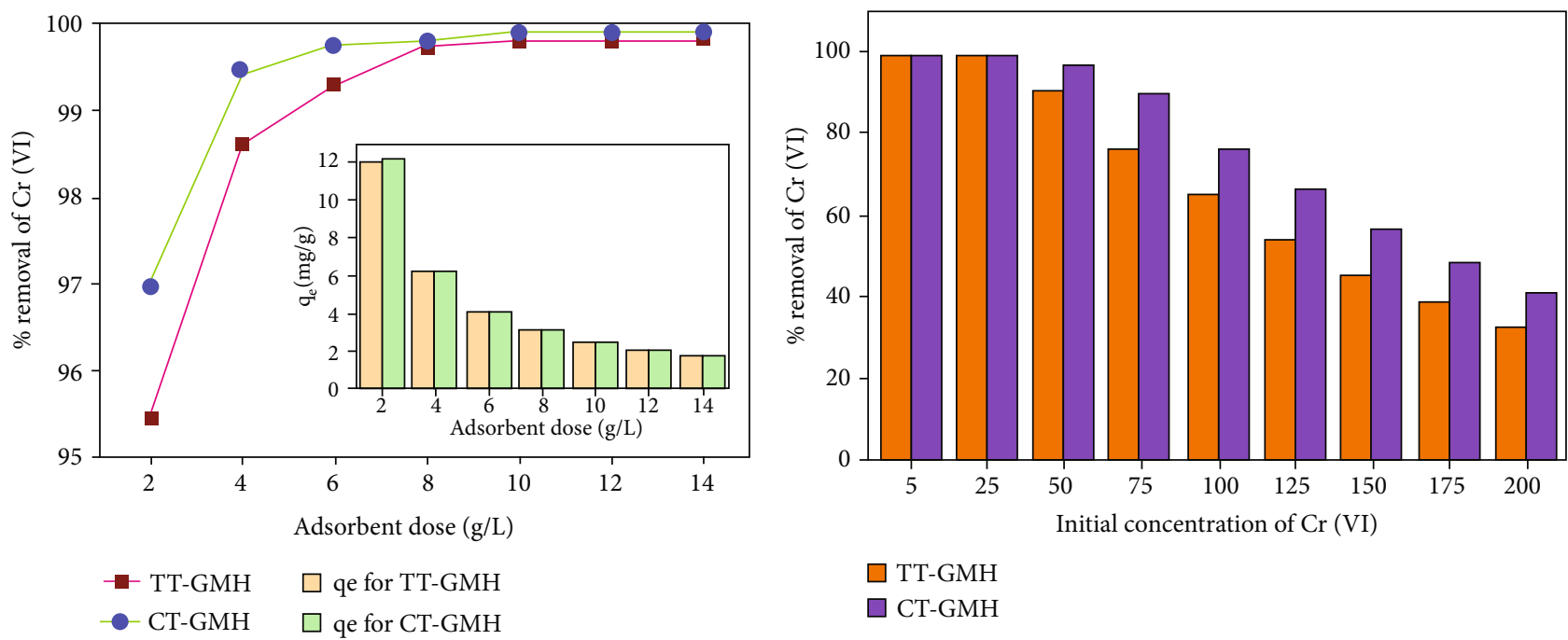

$\square$ TT-GMH

$\square$ CT-GMH

(c)

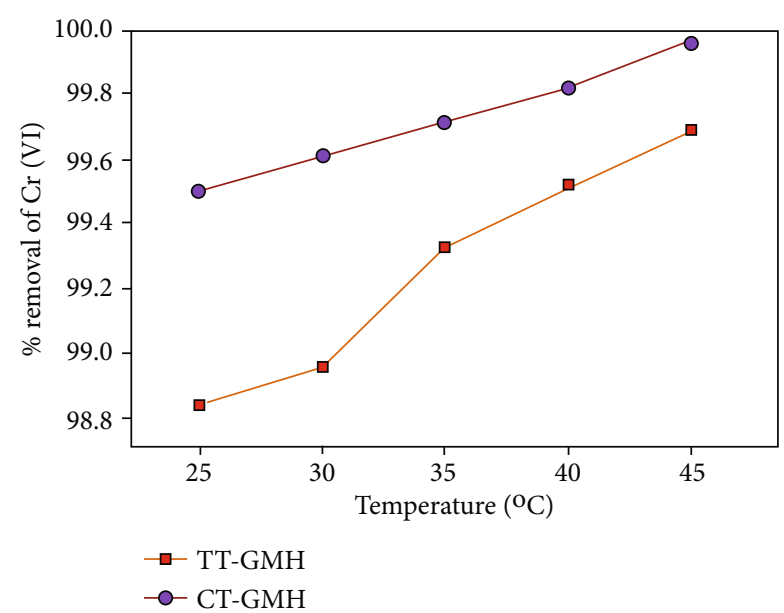

(e)

(f)

Figure 5: Effect of (a) contact time, (b) initial pH, (c) adsorbent dose, (d) concentration of $\mathrm{Cr}(\mathrm{VI})$, (e) temperature, and (f) RPM of batch adsorption process. 


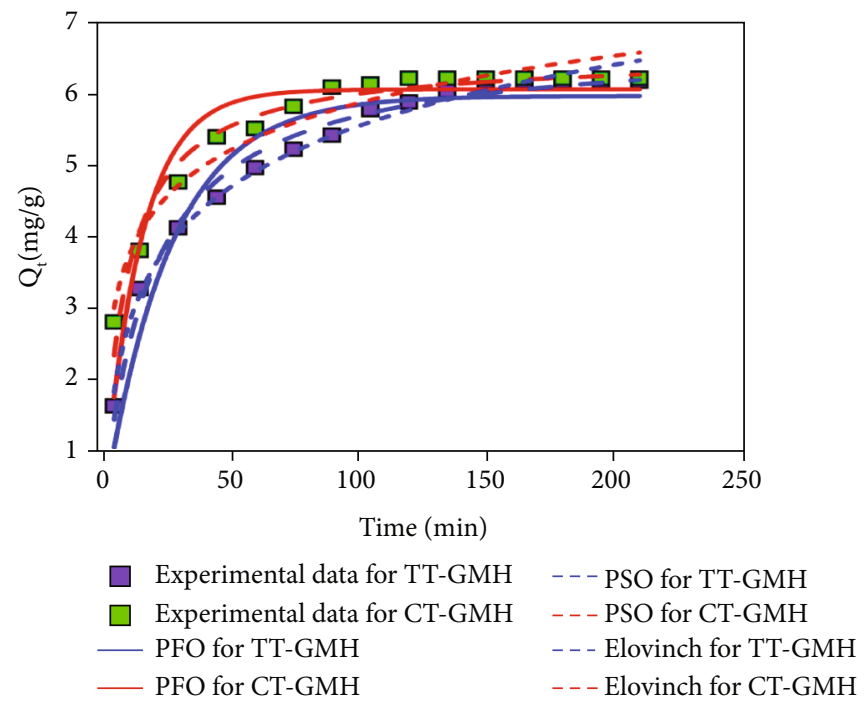

FIGURE 6: Nonlinear kinetic modeling for both the adsorbents.

TABLE 2: Kinetic parameters for adsorption of Cr(VI) onto TT-GMH and CT-GMH.

\begin{tabular}{|c|c|c|c|c|c|c|}
\hline \multirow{2}{*}{ Parameters } & \multicolumn{2}{|c|}{ Pseudo-first-order model } & \multicolumn{2}{|c|}{ Pseudo-second-order model } & \multicolumn{2}{|c|}{ Elovich model } \\
\hline & TT-GMH & CT-GMH & TT-GMH & CT-GMH & TT-GMH & CT-GMH \\
\hline$q_{\exp }$ & 6.580 & 6.418 & 6.580 & 6.418 & 6.580 & 6.418 \\
\hline$k_{1}$ & 0.038 & 0.068 & & & & \\
\hline$q_{\mathrm{e}}$ & 5.947 & 6.064 & 6.740 & 6.539 & & \\
\hline$k_{2}$ & & & 0.008 & 0.017 & & \\
\hline$\alpha$ & & & & & 1.078 & 4.419 \\
\hline$\beta$ & & & & & 0.804 & 1.045 \\
\hline$R^{2}$ & 0.9391 & 0.8706 & 0.9868 & 0.9688 & 0.9893 & 0.9516 \\
\hline$\chi$ & 0.11 & 0.06 & 0.02 & 0.01 & 0.29 & 0.33 \\
\hline
\end{tabular}

supported to the experimental data for both TT-GMH and CT-GMH adsorbents [41].

3.4. Adsorption Isotherm. Adsorption isotherms were studied to understand the phenomenon of adsorption. At fixed temperature, adsorption isotherms represent the equilibrium relation between the amount adsorbed per unit mass of adsorbent and the concentration of adsorbate. The experimental results were examined by three equilibrium isotherms such as Langmuir isotherm, Freundlich isotherm, and Sips isotherm to assess the most suitable equilibrium model for $\mathrm{Cr}(\mathrm{VI})$ adsorption onto great millet husk. The nonlinear equations of isotherms are given in supplementary material (Table S3). The results are shown in Figure 7(a) for TT-GMH and Figure 7(b) for CT-GMH. The parameters calculated for isotherms are presented in Table 3.

Langmuir isotherm is one of the simplest models of physical adsorption that is based on the assumption that only one molecule of adsorbate adsorbed at distinct active sites of the adsorbent and the adsorbed molecules are free from interaction among them [41]. Freundlich isotherm shows a nonlinear function between the amount adsorbed at equilibrium and some power of concentration of the solute. The Sips isotherm is derived as a combination and based on limiting behavior of both Langmuir and Freundlich isotherms [41-43]. The correlation coefficient $\left(R^{2}\right)$ for Langmuir, Freundlich, and Sips model for TT-GMH was noted to be $0.9616,0.8958$, and 0.9902 , respectively. And, for CT$\mathrm{GMH}$, the value of correlation coefficient was noted to be 0.9388, 0.9100, and 0.9883 for Langmuir, Freundlich, and Sips isotherms, respectively. Thus, based on the correlation coefficient $\left(R^{2}\right)$ and low error function $(\chi)$ values, the Sips model was found to be followed during adsorption of both TT-GMH and CT-GMH. The maximum uptake capacity based on Sips isotherm for TT-GMH and CT-GMH at temperature at $303 \mathrm{~K}$ was found to be $16.00 \mathrm{mg} / \mathrm{g}$ and $22.21 \mathrm{mg} /$ $\mathrm{g}$, respectively, for concentration of $\mathrm{Cr}(\mathrm{VI})$ in the range of 5$200 \mathrm{mg} / \mathrm{L}$ and at a fixed dose of adsorbents $(4 \mathrm{~g} / \mathrm{L})$.

3.5. Thermodynamic Parameters. Thermodynamic studies help us to determine the nature of adsorption of $\mathrm{Cr}(\mathrm{VI})$ onto TT-GMH and CT-GMH. For the adsorption process, the 


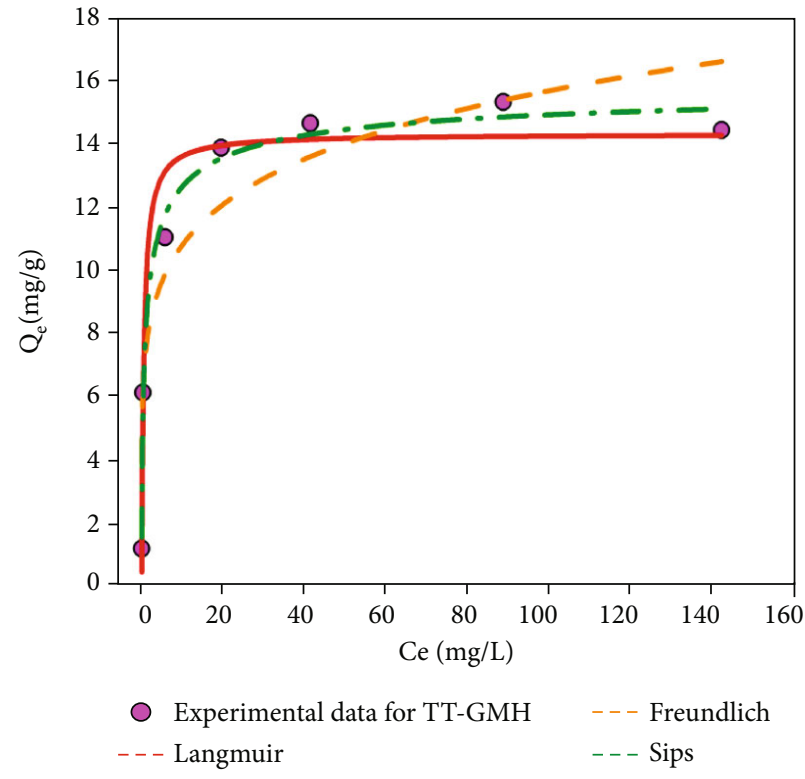

(a)

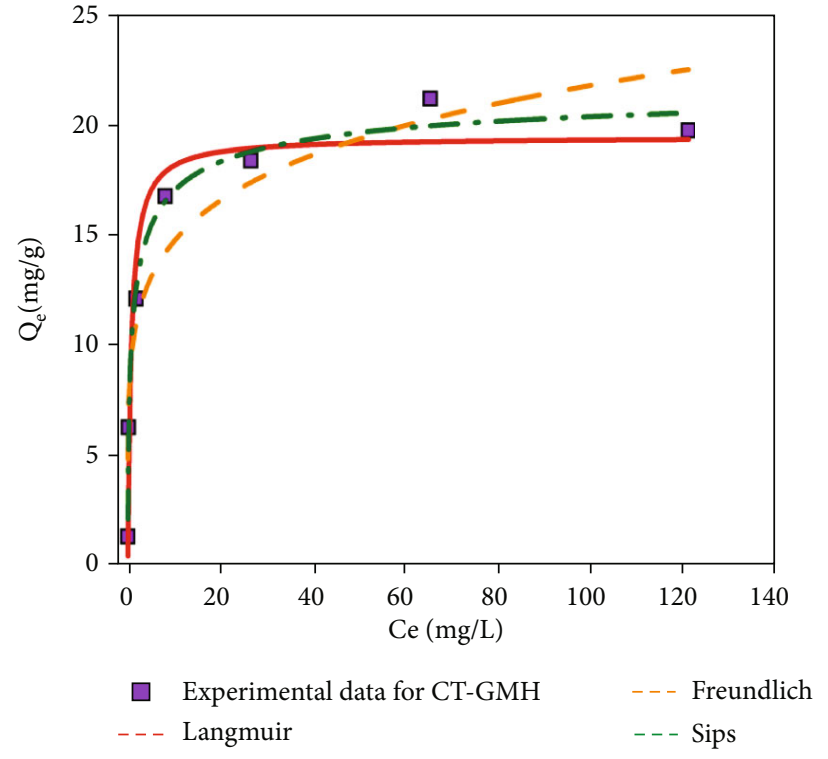

(b)

Figure 7: Adsorption isotherms for (a) TT-GMH and (b) CT-GMH.

TABLE 3: Isotherm parameters for adsorption of $\mathrm{Cr}(\mathrm{VI})$ onto TT-GMH and CT-GMH.

\begin{tabular}{|c|c|c|c|c|c|c|}
\hline \multirow{2}{*}{ Parameters } & \multicolumn{2}{|c|}{ Langmuir isotherm } & \multicolumn{2}{|c|}{ Freundlich isotherm } & \multicolumn{2}{|c|}{ Sips isotherm } \\
\hline & TT-GMH & CT-GMH & TT-GMH & CT-GMH & TT-GMH & CT-GMH \\
\hline$q_{\mathrm{m}}(\mathrm{mg} / \mathrm{g})$ & 14.33 & 19.418 & & & 16.001 & 22.212 \\
\hline$K_{\mathrm{L}}(\mathrm{L} / \mathrm{mg})$ & 1.918 & 1.396 & & & & \\
\hline$K_{\mathrm{f}}$ & & & 7.462 & 9.903 & & \\
\hline$N$ & & & 6.196 & 5.847 & & \\
\hline$K_{\mathrm{s}}$ & & & & & 1.034 & 0.9619 \\
\hline$m_{\mathrm{s}}$ & & & & & 0.5648 & 0.5276 \\
\hline$R^{2}$ & 0.9616 & 0.9388 & 0.8958 & 0.9100 & 0.9902 & 0.9883 \\
\hline$\chi$ & 1.03 & 4.89 & 1.32 & 3.38 & 0.81 & 0.76 \\
\hline
\end{tabular}

change in standard free energy $(\Delta G)$, enthalpy $(\Delta H)$, and entropy $(\Delta S)$ was calculated by using Eqs. (S7)-(S10) mentioned in Table S4 (supplementary material). The negative estimation of $\Delta G$ listed in Table 4 indicates the spontaneous adsorption of $\mathrm{Cr}(\mathrm{VI})$ onto the adsorbent and thermodynamic feasibility of the adsorption process [44]. A positive value of $\Delta H$ indicates that the process is endothermic in nature. Further, a positive value of $\Delta S$ refers to the increased randomness at the adsorbent-adsorbate interface during the adsorption of the $\mathrm{Cr}(\mathrm{VI})$ on both TTGMH and CT-GMH [20].

3.6. Mass Transfer Study. The equations of three different mass transfer models are shown in supplementary data (Table S5). The Weber and Morris model was generally known as the intraparticle diffusion model and normally used to understand the mechanism for mass transfer controlling steps involved in the adsorption of bulk $\mathrm{Cr}(\mathrm{VI})$ liquid to solid adsorbent (TT-GMH and CT-GMH) material (Prajapati \& Mondal, 2019). The nonlinear equation of the Weber and Morris model can be represented by Eq. (S11) (Supplementary material). The intraparticle diffusion constants $\left(K_{\mathrm{id}}\right)$ and intercept $(C)$ were calculated by plotting a graph between $q_{\mathrm{t}}$ and $t^{0.5}$; and if the plot was linear and passed through the origin of the axis $(0,0)$, then the ratecontrolling step was intraparticle diffusion. Otherwise, if the plot was linear but did not pass through the origin, the adsorption process involved some additional rate-control steps. It is clear from Figure 8(a) that the multilinearity plot did not pass through the origin and was divided into two sections for both TT-GMH and CT-GMH adsorbents, which confirmed that two or more controlling steps were involved in the mass transfer mechanism of $\mathrm{Cr}(\mathrm{VI})$ from bulk to solid [45], such as boundary layer diffusion and pore diffusion. The first section in the Weber-Morris plot described the film diffusion/pore diffusion, where $\mathrm{Cr}(\mathrm{VI})$ 
TABLE 4: Thermodynamic parameters at different temperatures for adsorption of Cr(VI) on TT-GMH and CT-GMH.

\begin{tabular}{lcccc}
\hline \multirow{2}{*}{ Adsorbent } & Thermodynamic parameters & 298 & Temperature & 308 \\
\hline \multirow{2}{*}{ TT-GMH } & $\Delta G^{0}(\mathrm{~kJ} / \mathrm{mol})$ & -11.03 & -11.78 & -12.76 \\
& $\Delta H^{0}(\mathrm{~kJ} / \mathrm{mol})$ & & 50.90 & -14.16 \\
& $\Delta S^{0}(\mathrm{~kJ} / \mathrm{mol} \cdot \mathrm{K})$ & & 207.31 & -14.46 \\
CT-GMH & $\Delta G^{0}(\mathrm{~kJ} / \mathrm{mol})$ & -13.14 & -13.75 & -16.33 \\
& $\Delta H^{0}(\mathrm{~kJ} / \mathrm{mol})$ & & 47.87 & 203.80 \\
\hline
\end{tabular}

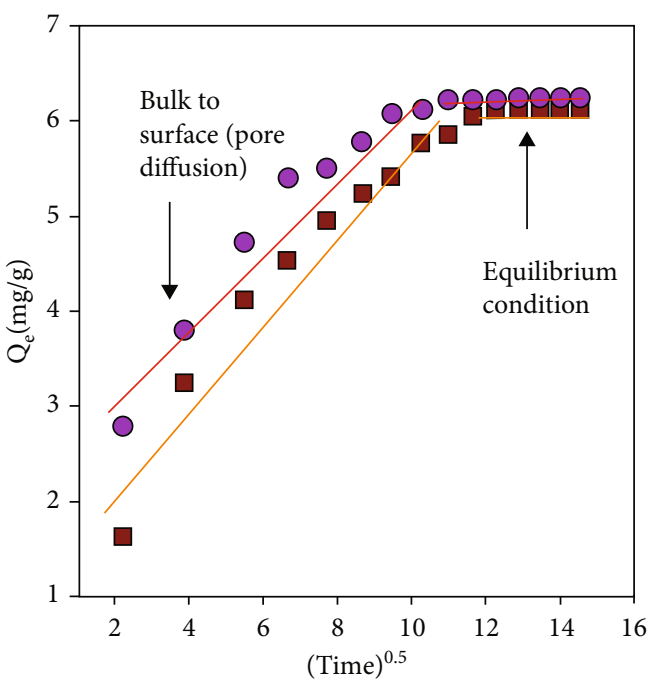

- TT-GMH

O CT-GMH

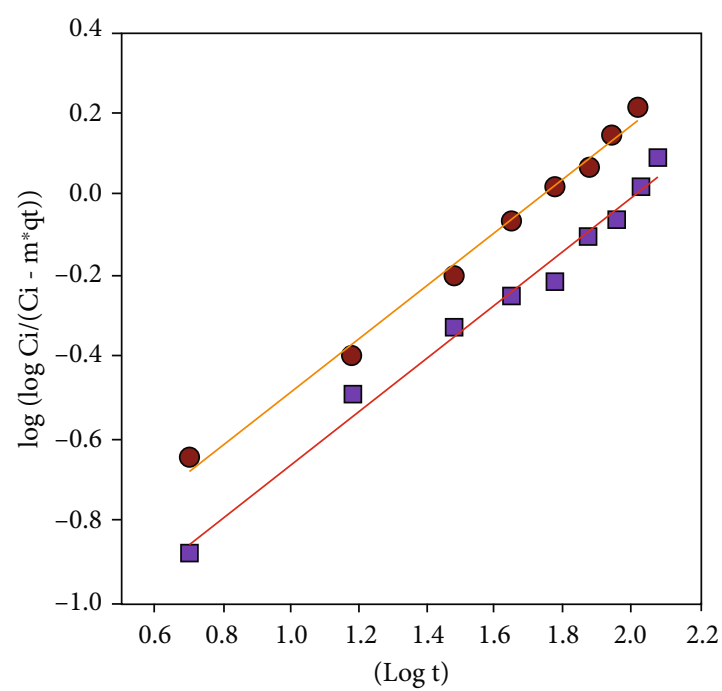

TT-GMH

- CT-GMH

(a)

(b)

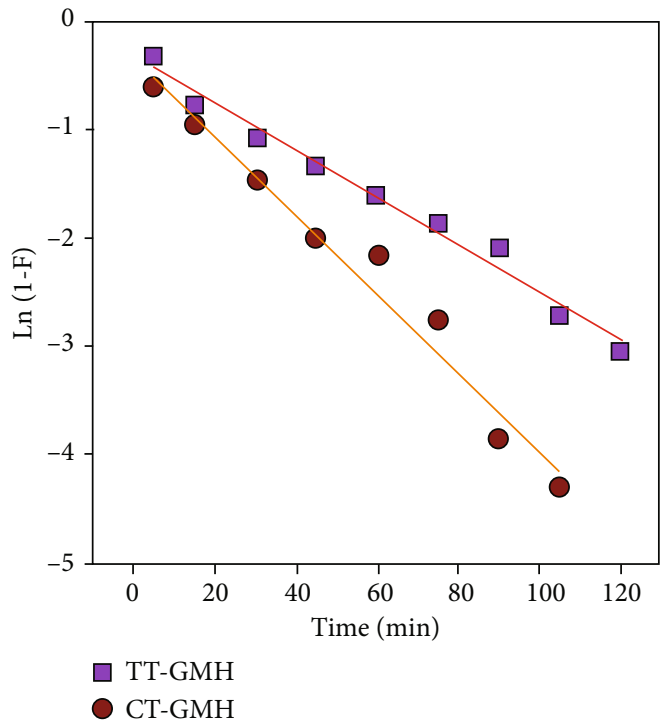

(c)

FIGURE 8: Mass transfer studies for adsorbents TT-GMH and CT-GMH: (a) Weber and Morris model, (b) Bangham and Burt model, and (c) layer/film diffusion model. 
TABLE 5: Mass transfer parameters for adsorption of $\mathrm{Cr}(\mathrm{VI})$ on TT-GMH and CT-GMH.

\begin{tabular}{|c|c|c|c|c|}
\hline \multirow{2}{*}{ Mass transfer model } & \multicolumn{4}{|c|}{ Adsorbents } \\
\hline & & Parameters & TT-GMH & CT-GMH \\
\hline \multirow{9}{*}{ (1) Weber \& Morris model } & \multirow{5}{*}{ First stage } & $K_{\mathrm{id}(1)}\left(\mathrm{mg} / \mathrm{g} \cdot \min ^{1 / 2}\right)$ & 0.449 & 0.386 \\
\hline & & $C_{1}$ & 1.274 & 2.369 \\
\hline & & $R_{1}^{2}$ & 0.942 & 0.939 \\
\hline & & $K_{\mathrm{id}(2)}\left(\mathrm{mg} / \mathrm{g} \cdot \mathrm{min}^{1 / 2}\right)$ & $2.21 \times 10^{-3}$ & $7.92 \times 10^{-4}$ \\
\hline & & $C_{2}$ & 6.147 & 6.211 \\
\hline & \multirow[t]{2}{*}{ Second stage } & $R_{2}^{2}$ & 0.928 & 0.964 \\
\hline & & $K_{\mathrm{id}(\mathrm{O})}\left(\mathrm{mg} / \mathrm{g} \cdot \min ^{1 / 2}\right)$ & 0.331 & 0.247 \\
\hline & \multirow{2}{*}{ Overall stage } & $C_{\mathrm{O}}$ & 2.01 & 3.22 \\
\hline & & $R_{\mathrm{O}}^{2}$ & 0.888 & 0.805 \\
\hline \multirow{3}{*}{ (2) Bangham's model } & & $K_{\mathrm{o}}(\mathrm{mL} /(\mathrm{g} / \mathrm{L}))$ & -1.359 & -1.145 \\
\hline & & $\alpha$ & 0.709 & 0.679 \\
\hline & & $R^{2}$ & 0.962 & 0.971 \\
\hline \multirow{3}{*}{ (3) Liquid film diffusion model } & & $K_{\mathrm{FD}}$ & -0.0220 & -0.0365 \\
\hline & & $C$ & -0.3184 & -0.3257 \\
\hline & & $R^{2}$ & 0.983 & 0.975 \\
\hline
\end{tabular}

ions were migrated from the solution to the outer solid surface of the both adsorbents (TT-GMH and CT-GMH). In the second section, the adsorption process attains equilibrium in the case of both adsorbents. Table 5 shows the values of the overall and sectional intraparticle rate constant, boundary layer thickness, and $R^{2}$ for both adsorbents. The boundary layer thickness $(C)$ values are higher for CT-GMH adsorbent (Table 5), which confirmed that the boundary-layer diffusion mechanism was encouraged in CT-GMH adsorbent for adsorption of $\mathrm{Cr}(\mathrm{VI})$.

If pore diffusion phenomena were involved during the adsorption process, then the Bangham and Burt model was employed to determine the rate-determining step [41]. The equation of the Bangham model is shown by Eq. (S12). Figure 8(b) shows the linear plots of Bangham's model for the TT-GMH and CT-GMH adsorbent. Table 5 shows the value of Bangham's constants and $R^{2}$ for TTGMH and CT-GMH adsorbents. According to the $R^{2}$ values, Bangham's model was not solely a rate-governing stage for $\mathrm{Cr}$ (VI) adsorption onto TT-GMH and CT-GMH adsorbents; therefore, both surface and pore diffusion may control it. Additionally, the $R^{2}$ value for CT-GMH is much higher than the TT-GMH adsorbent that indicates CTGMH shows more pore diffusion rate than TT-GMH due to the large number of pores on the surface of CT-GMH due to acid treatment.

The two-section curve of the Weber-Morris model indicated that liquid film/layer diffusion could have been the major factor for the adsorption of $\mathrm{Cr}$ (VI) by TT-GMH and CT-GMH adsorbents in the present study. Therefore, the film/layer diffusion model was employed to equilibrium time data for both adsorbents. Eq. (S13) denoted the layer film diffusion model. According to the layer diffusion mass trans- fer model, if the plot between $\ln (1-f)$ and $t$ was linear and passes through the origin $(0,0)$ axis, then liquid film diffusion was the only rate-controlling step in the adsorption of $\mathrm{Cr}(\mathrm{VI})$ by TT-GMH and CT-GMH adsorbents. Figure 8(c) and Table 5 show the linear fitted plot and estimated values of layer diffusion constants, respectively, for layer film diffusion. The liquid film diffusion plot for $\mathrm{Cr}(\mathrm{VI})$ adsorption by TT-GMH and CT-GMH adsorbents gave the linear plot for both adsorbents with high $R^{2}$ values compared to Weber-Morris and Bangham's model with negative diffusion constant and intercept values. This outcome confirmed that liquid film diffusion was a dominant factor for the rate-controlling step in the mass transfer of $\mathrm{Cr}(\mathrm{VI})$ into TT-GMH and CT-GMH adsorbents. According to $R^{2}$ (Table 5) values from three mass transfer models, the order of rate-controlling models was liquid film diffusion model $>$ Bangham's model > intraparticle diffusion model.

3.7. Possible Mechanism of Cr(VI) Adsorption onto TT-GMH and CT-GMH. The possible mechanism of $\mathrm{Cr}(\mathrm{VI})$ removal using TT-GMH and CT-GMH at $\mathrm{pH}$ lower $\mathrm{pH}_{\mathrm{pzc}}$ is shown in Figure 9. The initial adsorption process might occur due to electrostatic attraction between anionic ions of $\mathrm{Cr}(\mathrm{VI})$ and protonated surface of TT-GMH and CT-GMH at $\mathrm{pH}$ lower than $\mathrm{pH}_{\mathrm{pzc}}$. The FTIR results confirmed the association of $\mathrm{C}-\mathrm{O}$ bonds with both the adsorbents. There can be possibility of ion exchange and hydrogen bonding for uptake of $\mathrm{Cr}(\mathrm{VI})$ ions on the surface of adsorbents. Moreover, intraparticle pore diffusion also plays an important role in adsorption process. The groups associated with adsorbents such as $\mathrm{O}-\mathrm{H}, \mathrm{C}-\mathrm{H}$, and $\mathrm{C}-\mathrm{C}$ can acts as electron donors and effectively reduce $\mathrm{Cr}(\mathrm{VI})$ to $\mathrm{Cr}$ (III) (Li et al., 2017). At low $\mathrm{pH}$, chromium exists in the form of $\mathrm{HCrO}_{4}^{-}, \mathrm{CrO}_{4}^{2-}$, 


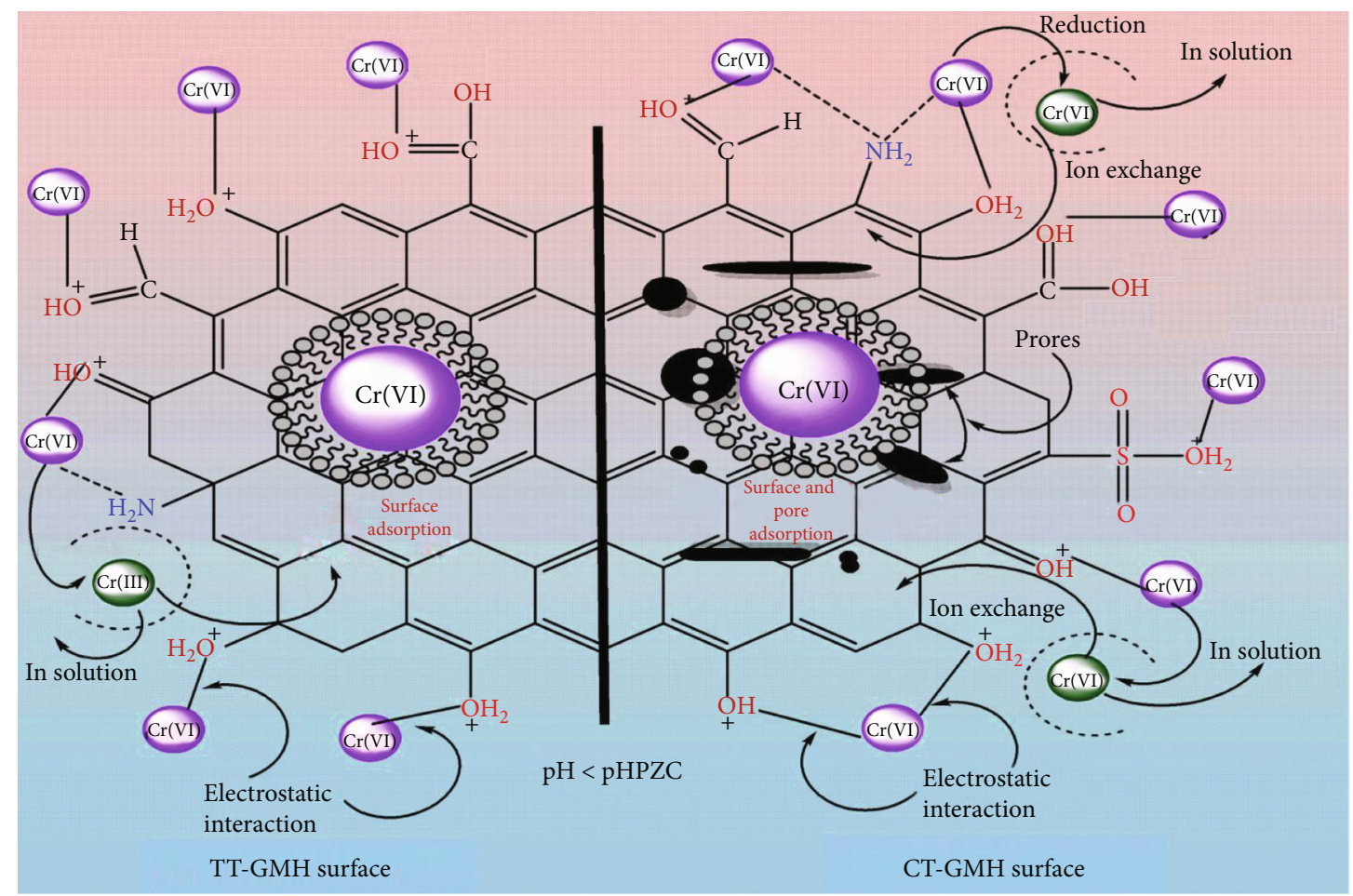

FIgURE 9: Adsorption and desorption study of adsorbents TT-GMH and CT-GMH.

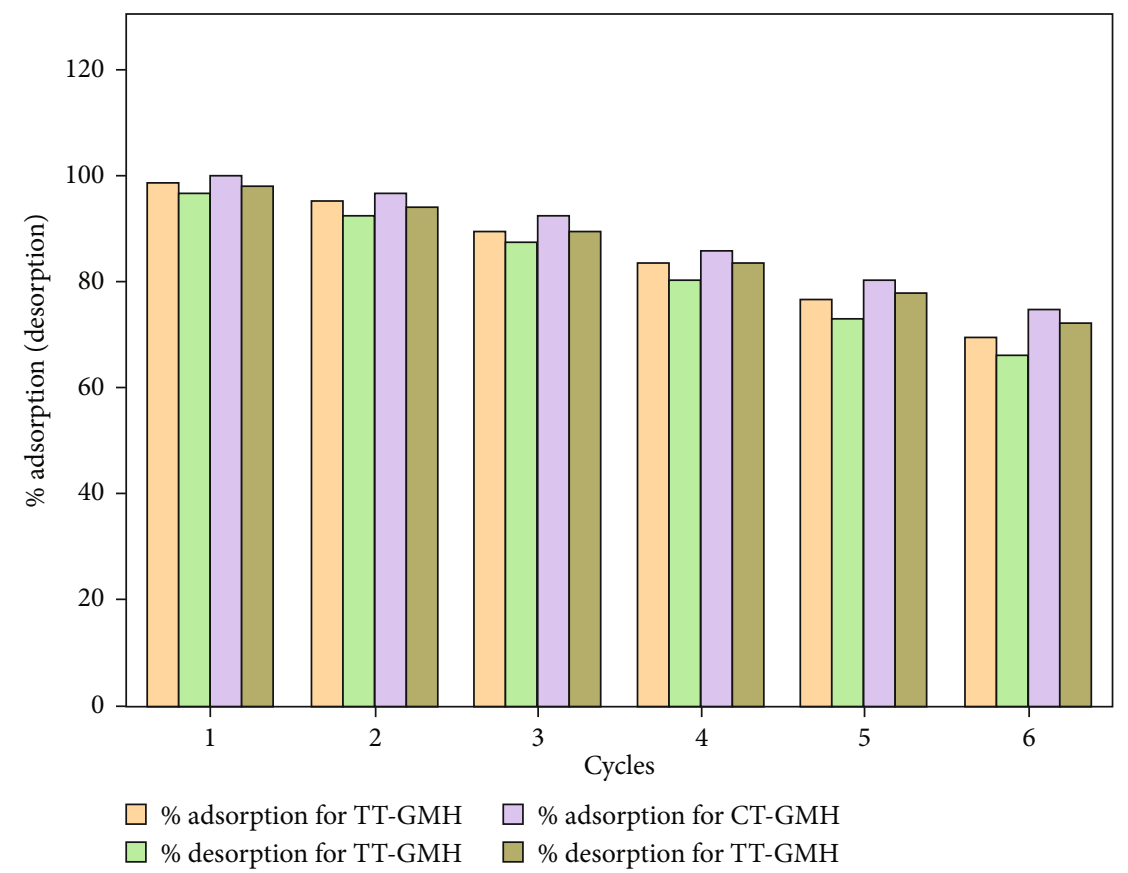

FIgUre 10: Adsorption and desorption study of adsorbents TT-GMH and CT-GMH.

and $\mathrm{Cr}_{2} \mathrm{O}_{7}^{-2}$. The reduction of $\mathrm{Cr}(\mathrm{VI})$ to $\mathrm{Cr}(\mathrm{III})$ can occur due to following reactions $[18,45]$ :

$$
\begin{gathered}
\mathrm{HCrO}_{4}^{-}+7 \mathrm{H}^{+}+3 \mathrm{e}^{-} \longrightarrow \mathrm{Cr}^{3+}+4 \mathrm{H}_{2} \mathrm{O} \\
\mathrm{CrO}_{4}^{2-}+8 \mathrm{H}^{+} \longrightarrow \mathrm{Cr}^{3+}+4 \mathrm{H}_{2} \mathrm{O} \\
\mathrm{Cr}_{-} 2 \mathrm{O}_{7}^{2-}+14 \mathrm{H}^{+}+6 \mathrm{e}^{-} 2 \longrightarrow \mathrm{Cr}^{3+}+7 \mathrm{H}_{2} \mathrm{O}
\end{gathered}
$$

The released $\mathrm{Cr}$ (III) ions are present in the solution. The adsorption of $\mathrm{Cr}(\mathrm{VI})$ was also confirmed by EDX analysis where chromium was detected on the surface of adsorbent (TT-GMH and CT-GMH) after adsorption. The adsorption in the case of CT-GMH is also supported by higher functionality of adsorbent due to chemical treatment. 
TABLE 6: Comparison of adsorption capacities of different adsorbents for the removal of $\mathrm{Cr}(\mathrm{VI})$.

\begin{tabular}{|c|c|c|c|c|c|}
\hline Adsorbent & Conc. (mg/L) & Temp. $\left({ }^{\circ} \mathrm{C}\right)$ & $\mathrm{pH}$ & Adsorption capacity $(\mathrm{mg} / \mathrm{g})$ & References \\
\hline Magnetic biochar composite & 100 & 25 & 3 & 8.35 & {$[47]$} \\
\hline Oak bark char & $1-100$ & 45 & 2 & 7.51 & {$[48]$} \\
\hline Biochar from Eucalyptus bark & $1-240$ & 30 & 2 & 21.3 & [49] \\
\hline Biochar from wheat straw & $1-600$ & 25 & 2 & 28.1 & {$[50]$} \\
\hline Rice husk biochar (surface modified) & $0.25-5$ & 50 & 7 & 4.54 & {$[51]$} \\
\hline Iron industry waste (dolochar) & $10-50$ & $35-70$ & 1 & 2.1 & {$[52]$} \\
\hline Wheat bran (calcined) & 50 & 25 & 2 & 7.6 & [53] \\
\hline Biochar from pyrolysis of biomass & $5-75$ & 25 & 1.5 & $3.53-6.08$ & {$[54]$} \\
\hline TT-GMH & $5-200$ & 25 & 1 & 16.00 & This study \\
\hline CT-GMH & $5-200$ & 25 & 2 & 22.21 & This study \\
\hline
\end{tabular}

3.8. Desorption Study. A desorption study for adsorbent is very crucial for reusability and ultimate disposal of used adsorbent. The desorption and readsorption study for $\mathrm{Cr}(\mathrm{VI})$ was performed using $0.1 \mathrm{M} \mathrm{NaOH}$ followed by $0.1 \mathrm{M} \mathrm{HCl}$ solution. The results are shown in Figure 10. It can be observed that TT-GMH and CT-GMH gives $69.45 \%$ and $74.48 \%$ removal, respectively, up to six cycles. In addition, desorption for TT-GMH and CT-GMH was observed to be $65.48 \%$ and $71.68 \%$, respectively, up to six cycles.

3.9. Comparison of Adsorption Capacities. Further adsorption capacities of different adsorbents reported in literature which are compared with the two adsorbents prepared from great millet husk are presented in Table 5. From Table 6, adsorption capacities of the present study are comparable with some of the values reported in literature. The equilibrium uptake of different adsorbents depends upon its characteristics. However, the present study was done to check the application of great millet husk for $\mathrm{Cr}(\mathrm{VI})$ removal.

\section{Conclusion}

This study presents the efficacy of two adsorbents prepared by thermally and chemically activated great millet husk for $\mathrm{Cr}$ (VI) removal. The maximum removal efficiency obtained for TT-GMH and CT-GMH was 98.84 and $99.50 \%$, respectively. The maximum adsorption capacity obtained for TTGMH was $16 \mathrm{mg} / \mathrm{g}$ whereas for CT-GMH, it was $22.21 \mathrm{mg} /$ $\mathrm{g}$ at an adsorbent dose of $4 \mathrm{~g} / \mathrm{L}$. The effect of $\mathrm{pH}$ variation demonstrated that for both the adsorbents (TT-GMH and CT-GMH), the adsorption process is highly $\mathrm{pH}$ dependent. Results showed that chemical modification of great millet husk is more effective than the thermal treatment. The higher surface area, pore volume, and functionality of CTGMH favor the higher uptake capacity towards $\mathrm{Cr}(\mathrm{VI})$ removal. Less equilibrium time for adsorption in the case of CT-GMH facilitates a cost-effective process at a large industrial scale. Comparison with uptake capacity of different adsorbents for $\mathrm{Cr}(\mathrm{VI})$ removal, reported in literature, showed that TT-GMH and CT-GMH of great millet husk can be considered one of the effective adsorbents for $\mathrm{Cr}(\mathrm{VI})$ removal. Experimental data designated the capability of TT-
GMH and CT-GMH for removal of Cr(VI) from wastewater. These adsorbents might be considered a valuable material for cost-effectiveness in the adsorption process.

\section{Data Availability}

Data are available on request to the corresponding author.

\section{Conflicts of Interest}

The authors declare that they have no competing interest.

\section{Authors' Contributions}

Anuj Kumar Prajapati was responsible for methodology and writing the original draft. Pushkar Verma was responsible for review and editing. Satyansh Singh was responsible for formal analysis, investigations, and editing. Monoj Kumar Mondal was responsible for the resources, supervision, and editing.

\section{Acknowledgments}

The authors are thankful to the Indian Institute of Technology (Banaras Hindu University), India, for providing all necessary facilities to undertake the work.

\section{Supplementary Materials}

Data presented in supplementary material of this paper are available on request to the corresponding author. (Supplementary Materials)

\section{References}

[1] S. K. Pradhan, V. Pareek, J. Panwar, and S. Gupta, "Synthesis and characterization of ecofriendly silver nanoparticles combined with yttrium oxide $\left(\mathrm{Ag}-\mathrm{Y}_{2} \mathrm{O}_{3}\right)$ nanocomposite with assorted adsorption capacity for $\mathrm{Cu}(\mathrm{II})$ and $\mathrm{Cr}(\mathrm{VI})$ removal: a mechanism perspective," Journal of Water Process Engineering, vol. 32, article 100917, 2019.

[2] S. Banerjee, S. R. Joshi, T. Manda, and G. Halder, "Application of zirconium caged activated biochar alginate beads towards 
deionization of $\mathrm{Cr}(\mathrm{VI})$ laden water in a fixed bed column reactor," Journal of Environmental Chemical Engineering, vol. 6, no. 4, pp. 4018-4029, 2018.

[3] L. Chen, S. Zhou, Y. Shi et al., "Heavy metals in food crops, soil, and water in the Lihe River Watershed of the Taihu Region and their potential health risks when ingested," Science of the Total Environment, vol. 615, pp. 141-149, 2018.

[4] R. Shan, Y. Shi, J. Gu et al., "Aqueous Cr(VI) removal by biochar derived from waste mangosteen shells: role of pyrolysis and modification on its absorption process," Journal of Environmental Chemical Engineering, vol. 8, no. 4, article 103885, 2020.

[5] U. K. Singh and B. Kumar, "Pathways of heavy metals contamination and associated human health risk in Ajay River basin, India," Chemosphere, vol. 174, pp. 183-199, 2017.

[6] H. Dong, Q. He, G. Zeng et al., "Chromate removal by surfacemodified nanoscale zero-valent iron: effect of different surface coatings and water chemistry," Journal of Colloid and Interface Science, vol. 471, pp. 7-13, 2016.

[7] B. Xie, C. Shan, Z. Xu et al., "One-step removal of $\mathrm{Cr}(\mathrm{VI})$ at alkaline $\mathrm{pH}$ by UV/sulfite process: reduction to $\mathrm{Cr}$ (III) and _in situ_Cr(III) precipitation," Chemical Engineering Journal, vol. 308, pp. 791-797, 2017.

[8] F. Yao, M. Jia, Q. Yang et al., "Electrochemical Cr(VI) removal from aqueous media using titanium as anode: simultaneous indirect electrochemical reduction of $\mathrm{Cr}(\mathrm{VI})$ and in-situ precipitation of Cr(III)," Chemosphere, vol. 260, article 127537, 2020.

[9] D. Mahringer, S. S. Zerelli, U. Dippon, and A. S. Ruhl, "Pilot scale hexavalent chromium removal with reduction, coagulation, filtration and biological iron oxidation," Separation and Purification Technology, vol. 253, article 117478, 2020.

[10] B. Ou, J. Wang, Y. Wu, S. Zhao, and Z. Wang, "Efficient removal of $\mathrm{Cr}$ (VI) by magnetic and recyclable calcined CoFe$\mathrm{LDH} / \mathrm{g}-\mathrm{C}_{3} \mathrm{~N}_{4}$ via the synergy of adsorption and photocatalysis under visible light," Chemical Engineering Journal, vol. 380, article 122600, 2020

[11] Z. Ying, X. Ren, J. Li, G. Wu, and Q. Wei, "Recovery of chromium(VI) in wastewater using solvent extraction with amide," Hydrometallurgy, vol. 196, article 105440, 2020.

[12] Y. Ren, Y. Han, X. Lei et al., "A magnetic ion exchange resin with high efficiency of removing Cr (VI)," Colloids and Surfaces A: Physicochemical and Engineering Aspects, vol. 604, article 125279, 2020.

[13] P. Y. He, Y. J. Zhang, H. Chen, Z. C. Han, and L. C. Liu, "Lowcost and facile synthesis of geopolymer-zeolite composite membrane for chromium(VI) separation from aqueous solution," Journal of Hazardous Materials, vol. 392, article 122359, 2020.

[14] G. López-Téllez, C. E. Barrera-Díaz, P. Balderas-Hernández, G. Roa-Morales, and B. Bilyeu, "Removal of hexavalent chromium in aquatic solutions by iron nanoparticles embedded in orange peel pith," Chemical Engineering Journal, vol. 173, no. 2, pp. 480-485, 2011.

[15] A. Zhang, X. Li, J. Xing, and G. Xu, “Adsorption of potentially toxic elements in water by modified biochar: a review," Journal of Environmental Chemical Engineering, vol. 8, no. 4, article 104196, 2020.

[16] D. Hopkins and K. Hawboldt, "Biochar for the removal of metals from solution: a review of lignocellulosic and novel marine feedstocks," Journal of Environmental Chemical Engineering, vol. 8, no. 4, article 103975, 2020.
[17] R. Apiratikul and P. Pavasant, "Batch and column studies of biosorption of heavy metals by _Caulerpa lentillifera_," Bioresource Technology, vol. 99, no. 8, pp. 2766-2777, 2008.

[18] A. K. Prajapati, S. Das, and M. K. Mondal, "Exhaustive studies on toxic $\mathrm{Cr}(\mathrm{VI})$ removal mechanism from aqueous solution using activated carbon of _Aloe vera_waste leaves," Journal of Molecular Liquids, vol. 307, article 112956, 2020.

[19] A. K. Prajapati and M. K. Mondal, "Hazardous As(III) removal using nanoporous activated carbon of waste garlic stem as adsorbent: kinetic and mass transfer mechanisms," Korean Journal of Chemical Engineering, vol. 36, no. 11, pp. 19001914, 2019.

[20] L. Chandana, K. Krushnamurty, D. Suryakala, and C. Subrahmanyam, "Low-cost adsorbent derived from the coconut shell for the removal of hexavalent chromium from aqueous medium," Materials Today: Proceedings, vol. 26, pp. $44-51,2020$.

[21] U. Khalil, M. S. Bilal, S. Ali, M. Rizwan, M. N. Alyemeni, and L. Wijaya, "Adsorption-reduction performance of tea waste and rice husk biochars for $\mathrm{Cr}(\mathrm{VI})$ elimination from wastewater," Journal of Saudi Chemical Society, vol. 24, no. 11, pp. 799-810, 2020.

[22] C. Lin, W. Luo, T. Luo, Q. Zhou, H. Li, and L. Jing, “A study on adsorption of $\mathrm{Cr}$ (VI) by modified rice straw: characteristics, performances and mechanism," Journal of Cleaner Production, vol. 196, pp. 626-634, 2018.

[23] K. Zhang, A. Khan, P. Sun, Y. Zhang, A. Taraqqi-A-Kamal, and Y. Zhang, "Simultaneous reduction of $\mathrm{Cr}(\mathrm{VI})$ and oxidization of organic pollutants by rice husk derived biochar and the interactive influences of coexisting $\mathrm{Cr}(\mathrm{VI})$, , Science of the Total Environment, vol. 706, article 135763, 2020.

[24] M. A. López Zavala, H. Romero-Santana, and B. E. MonárrezCordero, "Removal of $\mathrm{Cr}(\mathrm{VI})$ from water by adsorption using low cost clay-perlite-iron membranes," Journal of Water Process Engineering, vol. 38, article 101672, 2020.

[25] M. Banerjee, R. K. Basu, and S. K. Das, “Cr(VI) adsorption by a green adsorbent walnut shell: adsorption studies, regeneration studies, scale-up design and economic feasibility," Process Safety and Environmental Protection, vol. 116, pp. 693-702, 2018.

[26] R. Labied, O. Benturki, A. E. Hamitouche, and A. Donnot, "Adsorption of hexavalent chromium by activated carbon obtained from a waste lignocellulosic material (Ziziphus jujubacores): kinetic, equilibrium, and thermodynamic study," Adsorption Science \& Technology, vol. 36, no. 3-4, pp. 10661099, 2018.

[27] J. Badillo-Camacho, E. Orozco-Guareno, G. G. Carbajal-Arizaga, R. Manriquez-Gonzalez, I. D. Barcelo-Quintal, and S. Gomez-Salazar, "Cr(VI) adsorption from aqueous streams on eggshell membranes of different birds used as biosorbents," Adsorption Science \& Technology, vol. 38, no. 9-10, pp. 413434, 2020.

[28] S. Singh, J. P. Chakraborty, and M. K. Mondal, "Torrefaction of woody biomass (_Acacia nilotica_): investigation of fuel and flow properties to study its suitability as a good quality solid fuel," Renewable Energy, vol. 153, pp. 711-724, 2020.

[29] R. Narayan, R. P. Meena, A. K. Patel, A. K. Prajapati, S. Srivastava, and M. K. Mondal, "Characterization and application of biomass gasifier waste material for adsorptive removal of $\mathrm{Cr}$ (VI) from aqueous solution," Environmental Progress \& Sustainable Energy, vol. 35, no. 1, pp. 95-102, 2016. 
[30] S. Singh, J. P. Chakraborty, and M. K. Mondal, "Optimization of process parameters for torrefaction of A _cacia nilotica using response surface methodology and characteristics of torrefied biomass as upgraded fuel," Energy, vol. 186, article 115865, 2019.

[31] V. K. Gupta, A. Rastogi, and A. Nayak, "Adsorption studies on the removal of hexavalent chromium from aqueous solution using a low cost fertilizer industry waste material," Journal of Colloid and Interface Science, vol. 342, no. 1, pp. 135-141, 2010.

[32] F. Gorzin and A. Ghoreyshi, "Synthesis of a new low-cost activated carbon from activated sludge for the removal of $\mathrm{Cr}$ (VI) from aqueous solution: equilibrium, kinetics, thermodynamics and desorption studies," Korean Journal of Chemical Engineering, vol. 30, no. 8, pp. 1594-1602, 2013.

[33] K. R. Reddy, T. Xie, and S. Dastgheibi, "Adsorption of mixtures of nutrients and heavy metals in simulated urban stormwater by different filter materials," Journal of Environmental Science and Health, Part A, vol. 49, no. 5, pp. 524-539, 2014.

[34] U. K. Garg, M. Kaur, V. Garg, and D. Sud, "Removal of hexavalent chromium from aqueous solution by agricultural waste biomass," Journal of Hazardous Materials, vol. 140, no. 1-2, pp. 60-68, 2007.

[35] S. Larous, A. H. Meniai, and M. B. Lehocine, "Experimental study of the removal of copper from aqueous solutions by adsorption using sawdust," Desalination, vol. 185, no. 1-3, pp. 483-490, 2005.

[36] A. K. Bhattacharya, S. N. Mandal, and S. K. Das, "Adsorption of $\mathrm{Zn}$ (II) from aqueous solution by using different adsorbents," Chemical Engineering Journal, vol. 123, no. 1-2, pp. 43-51, 2006.

[37] K. Kadirvelu and C. Namasivayam, “Activated carbon from coconut coirpith as metal adsorbent: adsorption of $\mathrm{Cd}(\mathrm{II})$ from aqueous solution," Advances in Environmental Research, vol. 7, no. 2, pp. 471-478, 2003.

[38] N. Tewari, P. Vasudevan, and B. Guha, "Study on biosorption of $\mathrm{Cr}(\mathrm{VI})$ by _Mucor hiemalis_, Biochemical Engineering Journal, vol. 23, no. 2, pp. 185-192, 2005.

[39] M. E. Argun, S. Dursun, C. Ozdemir, and M. Karatas, "Heavy metal adsorption by modified oak sawdust: thermodynamics and kinetics," Journal of Hazardous Materials, vol. 141, no. 1, pp. 77-85, 2007.

[40] V. K. Gupta, S. Agarwal, and T. A. Saleh, "Synthesis and characterization of alumina-coated carbon nanotubes and their application for lead removal," Journal of Hazardous Materials, vol. 185 , no. 1, pp. 17-23, 2011.

[41] A. K. Prajapati and M. K. Mondal, "Comprehensive kinetic and mass transfer modeling for methylene blue dye adsorption onto $\mathrm{CuO}$ nanoparticles loaded on nanoporous activated carbon prepared from waste coconut shell," Journal of Molecular Liquids, vol. 307, article 112949, 2020.

[42] S. Singh, A. K. Prajapati, J. P. Chakraborty, and M. K. Mondal, "Adsorption potential of biochar obtained from pyrolysis of raw and torrefied Acacia nilotica towards removal of methylene blue dye from synthetic wastewater," Biomass Conversion and Biorefinery, 2021.

[43] Z. Shahryari, A. S. Goharrizi, and M. Azadi, "Experimental study of methylene blue adsorption from aqueous solutions onto carbon nano tubes," International Journal of Water Research, vol. 2, pp. 016-028, 2010.
[44] Y. Wang, Y. Gao, Z. Zhu et al., "Enhanced arsenic removal from aqueous solution by $\mathrm{Fe} / \mathrm{Mn}-\mathrm{C}$ layered double hydroxide composite," Adsorption Science \& Technology, vol. 2021, pp. 1-12, 2021.

[45] A. K. Prajapati and M. K. Mondal, "Novel green strategy for $\mathrm{CuO}-\mathrm{ZnO}-\mathrm{C}$ nanocomposites fabrication using marigold (Tagetes spp.) flower petals extract with and without CTAB treatment for adsorption of $\mathrm{Cr}(\mathrm{VI})$ and Congo red dye," Journal of Environmental Management, vol. 290, article 112615, 2021.

[46] A. A. Oladipo, E. O. Ahaka, and M. Gazi, "High adsorptive potential of calcined magnetic biochar derived from banana peels for $\mathrm{Cu}^{2+}, \mathrm{Hg}^{2+}$, and $\mathrm{Zn}^{2+}$ ions removal in single and ternary systems," Environmental Science and Pollution Research, vol. 26, no. 31, pp. 31887-31899, 2019.

[47] F. Wang, L. Y. Liu, F. Liu, L. G. Wang, T. Ouyang, and C. T. Chang, "Facile one-step synthesis of magnetically modified biochar with enhanced removal capacity for hexavalent chromium from aqueous solution," Journal of the Taiwan Institute of Chemical Engineers, vol. 81, pp. 414-418, 2017.

[48] D. Mohan, S. Rajput, V. K. Singh, P. H. Steele, and C. U. Pittman Jr., "Modeling and evaluation of chromium remediation from water using low cost bio- char, a green adsorbent," Journal of Hazardous Materials, vol. 188, no. 1-3, pp. 319-333, 2011.

[49] B. Choudhary and D. Paul, "Isotherms, kinetics and thermodynamics of hexavalent chromium removal using biochar," Journal of Environmental Chemical Engineering, vol. 6, no. 2, pp. 2335-2343, 2018.

[50] A. Tytłak, P. Oleszczuk, and R. Dobrowolski, "Sorption and desorption of $\mathrm{Cr}(\mathrm{VI})$ ions from water by biochars in different environmental conditions," Environmental Science and Pollution Research, vol. 22, no. 8, pp. 5985-5994, 2015.

[51] A. Sarkar, A. Ranjan, and B. Paul, "Synthesis, characterization and application of surface-modified biochar synthesized from rice husk, an agro-industrial waste for the removal of hexavalent chromium from drinking water at near-neutral $\mathrm{pH}$," Clean Technologies and Environmental Policy, vol. 21, no. 2, pp. 447-462, 2019.

[52] L. Panda, B. Das, D. Rao, and B. Mishra, "Application of dolochar in the removal of cadmium and hexavalent chromium ions from aqueous solutions," Journal of Hazardous Materials, vol. 192, no. 2, pp. 822-831, 2011.

[53] F. Ogata, N. Nagai, R. Itami, T. Nakamura, and N. Kawasaki, "Potential of virgin and calcined wheat bran biomass for the removal of chromium(VI) ion from a synthetic aqueous solution," Journal of Environmental Chemical Engineering, vol. 8, no. 2, article 103710, 2020.

[54] H. Deveci and Y. Kar, "Adsorption of hexavalent chromium from aqueous solutions by bio-chars obtained during biomass pyrolysis," Journal of Industrial and Engineering Chemistry, vol. 19, no. 1, pp. 190-196, 2013. 